\title{
Synthesis and Mesomorphic Properties of Side Chain Liquid-Crystalline Biphenyl-Phenyl Polyacrylates
}

\author{
Olga M. S. Ritter, Nádya P. da Silveira and Aloir A. Merlo* \\ Instituto de Química, Universidade Federal do Rio Grande do Sul, Av. Bento Gonçalves, 9500, Campus do Vale, \\ 91501-970 Porto Alegre-RS, Brazil
}

\begin{abstract}
A síntese e a caracterização de dois cristais líquidos poliacrilatos, de cadeia lateral contendo o sistema bifenil-fenila como unidade central são descritos. A cadeia terminal é derivada da L-isoleucina. Em cada caso, o espaçador undecila foi utilizado para conectar o grupo mesogênico e a cadeia polimérica. Ambos os polímeros apresentaram mesofase esmética A. Encontrou-se uma dependência entre as propriedades transicionais e parâmetros estruturais, tais como, flexibilidade da cadeia polimérica e conectividade da cadeia terminal quiral.
\end{abstract}

The synthesis and characterization of two chiral side-chain liquid crystal based on polyacrylates having a biphenyl-phenyl system as a core unit are described. The chiral terminal chain is derived from L-isoleucine. In each case an undecyl spacer was used to connect the mesogenic group to the backbone. Smectic A phase was found for both polymers. The transitional properties were dependent on structural parameters such as backbone flexibility and chiral terminal chain connectivity.

Keywords: chiral polyacrylates, L-isoleucine, synthesis, liquid crystal

\section{Introduction}

Liquid crystals science is a field of human knowledge that emerged at the end of the $19^{\text {th }}$ century when the Austrian botanist Friedrich Reinitzer ${ }^{1}$ reported from his microscopic observation the unusual thermal behavior of the molten sample of cholesteryl benzoate. This first observation of optical anisotropies phenomena in organic compounds opened a new and fascinating class of soft materials which combines extraordinary optical, elastic and viscous properties.

Liquid crystals are systems that can self-organize due to mesogenic groups which show short and long range collective interactions among them. This is the origin of interesting liquid crystals properties which were exploited extensively in the earlier 70's in TN-LC technology.,2,3 Nowadays, the LC displays are found everywhere such as watches, clocks, calculators, portable notebooks computers, vehicle clocks, speedometers, navigation and positional aids, mobile phones, flat desktop monitors, wave plates, polarizers, notch filters, etc. The LC technology has dominated the display market due to their

*e-mail: aloir@iq.ufrgs.br compactness, low weight, low-voltage operation, and lower power consumption. In our technological society, LC displays provide an interface between humans and machines and are expected to play an even bigger role in the future as the need of displaying information grows. The need of developing LC materials, batteries, polarizers, electrodes, semi-conductor, compensation films, spacers, etc for those applications mentioned before has been the main driving force behind $\mathrm{LC}$ research. LC science growth was dependent on the parallel progress and development of other fields of science such as synthetic organic chemistry, electronics, physics and device engineering.

Concerning LC materials, there are basically two types of concepts related to the design and synthesis: $(i)$ development of non-polymeric liquid crystals which are extensively used in LC displays as fast active devices when the change in molecular orientation with an applied field is required; (ii) development of polymeric liquid crystals to be explored for passive device applications in which no switching is involved. The control of molecular order and macroscopic orientation are ensured by the polymer network.

In regard to chemical structure, thermotropic LC polymers can be categorized into main-chain and sidechain polymers. Both categories combine electro-optical 
properties of low molecular weight liquid crystals with mechanical properties and easy processing of polymers. ${ }^{4}$ The new concept of liquid-crystalline polymeric materials was first introduced in parallel by the groups of Shibaev and Finkelmann ${ }^{5}$ at the end of 70's. They recognized that the polymer materials could exhibit the liquid-crystalline properties if the mesogenic unit was linked to the polymer backbone via a flexible spacer. They conducted systematic studies of side-chain liquid-crystalline polymers and have proved that the liquid crystals order is preserved if the flexible spacer group is inserted between the main chain and mesogenic core. The concept of SCLCP is basically centered on decoupling motion of main chain and mesogenic side chain. This means that there is little or no molecular orientation restriction of mesogenic group in relation to the main chain.

The first chiral side chain liquid crystal polymer was reported in 1984 by Shibaev et al..$^{6}$ Like non-polymeric liquid crystals these polymers can exhibit smectic, nematic and cholesteric phases. Such polymers can be used for optical storage ${ }^{7}$ and infrared imaging. ${ }^{8}$ Because of their polymeric nature these materials show a glass transition in which the liquid-crystalline phase is frozen in the glassy state and normally do not crystallize at lower temperatures. In the applications in which field-induced molecular orientation is not involved, it would be interesting to maintain molecular order over a long period of time by mesophase fixation in the glassy matrix to avoid light scattering present in a polycrystalline film. ${ }^{9}$

In previous papers, we have reported the synthesis and mesomorphic behavior of a series of chiral liquid crystals polymers with different flexible spacer groups as well as chiral terminal chains..$^{10,11}$ The phase behavior was dependent on the molecular relationships among the polymer backbone, the terminal group attached to mesogenic group and the molecular mass. The polymers under analysis consisted of a poly(acrylic acid) backbone, to which the mesogenic units were linked by a spacer group. It is well known that the nature of mesophases depends on the relationship established between polymer backbone, mesogenic core and the length of the flexible spacer group. To establish the correlation between the structural aspects of the polymer and the LC properties, we have designed new acrylates $\mathbf{1 0}$ and $\mathbf{1 1}$ and their homopolymers $\mathbf{1 2}$ and $\mathbf{1 3}$.

In this paper we will describe the synthesis and the phase behavior of a novel series of side-chain chiral liquid crystals polymers $\mathbf{1 2}$ and $\mathbf{1 3}$ with their general chemical formula as showing in Figure 1.

The liquid crystals monomers $\mathbf{1 0}$ and $\mathbf{1 1}$ and the corresponding polymers $\mathbf{1 2}$ and $\mathbf{1 3}$ are composed of a biphenyl moiety linked with a phenyl moiety via an ester

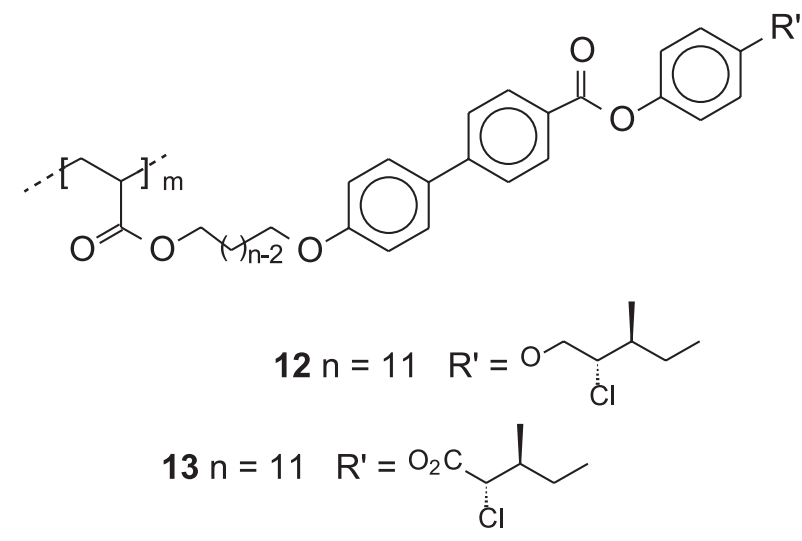

Figure 1. Molecular structure of polymers $\mathbf{1 2}$ and $\mathbf{1 3 .}$

linkage as a mesogenic core and an undecamethylene chain as a spacer. Meanwhile, the LC groups $\mathbf{1 0}$ and $\mathbf{1 2}$ are composed of an ether chiral moiety and LC groups $\mathbf{1 1}$ and $\mathbf{1 3}$ are composed of an ester chiral moiety. Both derived from aminoacid L-Isoleucine.

\section{Results and Discussion}

\section{Synthesis}

The synthetic approach for the synthesis of the chiral precursor $\mathbf{4 b}$ is based on the use of the aminoacid as a chiral source. The aminoacid, L-Isoleucine (1) was transformed into chiral intermediate $\mathbf{2}$ under diazotization conditions $\left(\mathrm{NaNO}_{2} / \mathrm{HCl}\right)$ in $67 \%$ yield. The next step was the time-controlled lithium aluminum hydride reduction procedure developed by Koppenhoefer and Schurig ${ }^{12}$ yielding the chiral 2-chloroalcohol (3) in 57\% yields, according to Scheme 1 . This procedure was used to prevent hydrogenolysis of the chlorine-carbon bond. ${ }^{13}$

The stereochemical outcome of chlorination reaction by diazonium salt reaction was confirmed by proton NMR analysis. From ${ }^{1} \mathrm{H}$ NMR (300 MHz) spectrum we could observe a signal in $4.24 \mathrm{ppm}$ as duplete and $J_{\mathrm{H \alpha H \beta}}=6,34 \mathrm{~Hz}$. No other signal was detected in this spectral region indicating a diastereomeric excess of $>95 \%$. Nucleophilic substitution

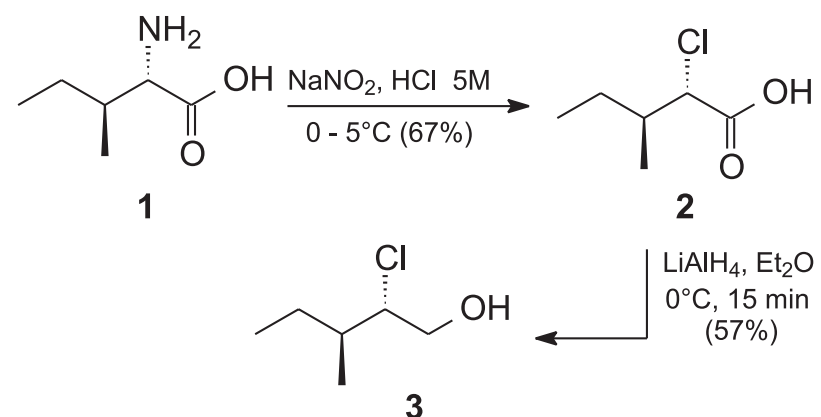

Scheme 1. Synthesis of key intermediates for LC materials. 
took place with retention of the configuration ${ }^{14-16}$ by means of double configuration inversion of unstable $\alpha$-lactone.

The synthesis of key intermediate $\mathbf{4 b}$ was achieved by Mitsunobu reaction, ${ }^{17}$ starting from hydroquinone monobenzoate $6^{18}$ and chiral chloroalcohol 3 . The reaction conditions for synthesis of compound 4a under Mitsunobu coupling were established according to reference 11 . The compound 4 a was obtained in $52 \%$ yield after chromatographic column. Basic hydrolyse afforded (2S,3S)-(+)-4-[(2-chloro-3-methyl)pentyloxy]phenol (4b) in $74 \%$ yield.

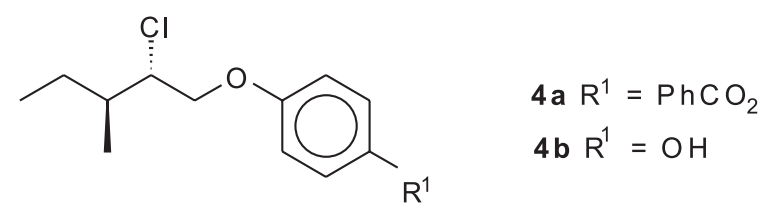

The stereochemistry of intermediate $\mathbf{4 a}$ was established unequivocally by single-crystal X-ray structure determination, ${ }^{11}$ showing that the nucleophilic displacement of chiral diazonium salts in Scheme 1 proceeds with overall retention of configuration.

The hydroquinone monobenzoate (6) was synthesized in $63 \%$ of yield by conversion of $\mathbf{5}$ into the acyl derivative followed by reaction with hydroquinone in pyridine, according to Scheme 2.

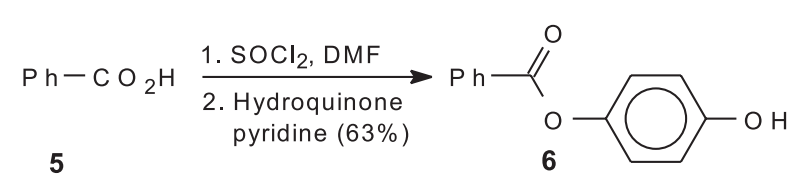

Scheme 2. Synthesis of hydroquinone monoprotected 6

The synthesis of chiral ester 7 was accomplished by exposure of $\alpha$-chloro acid $\mathbf{2}$ to $\mathrm{SOCl}_{2}$ solution and then hydroquinone in the presence of DMAP and pyridine as a solvent. Product 7 was obtained in $35 \%$ yield and $[\alpha]{ }_{D}^{20}=$ $+16.0\left(1, \mathrm{CH}_{2} \mathrm{Cl}_{2}\right)$. The use of DCC-DMAP protocol and DCM or THF as a solvent was tried but the yield was lower than acyl chloride method. Moreover, the enantiomeric excess of this kind of reaction depends on the method of esterification as reported in literature. ${ }^{16} \mathrm{We}$ anticipated that the low yields of $\mathbf{7}$ are mainly due to the high instability of acyl chloride derivative and the poor solubility of hydroquinone.

To incorporate the rigid aromatic ring at the central position relative to the flexible chain in (+)-4b and (+)-7,<smiles>CCC(C)[C@H](Cl)C(=O)Oc1ccc(O)cc1</smiles>

a biphenyl system was synthesized and then coupled with the chiral phenol $\mathbf{4 b}$ and $\mathbf{7}$ by DCC-DMAP protocol. The carboxylic acid $\mathbf{9}$ was used as rigid core and it was synthesized from 4'-hydroxybiphenyl-4-carboxylic acid (8) in a four step procedure depicted in Scheme 3. First, the acid $\mathbf{8}$ was converted into the ethyl ester by classical Fischer esterification (quantitative) ${ }^{19} \mathrm{Next}$, the ethyl ester containing the spacer group was prepared by alkylation reaction ${ }^{20}$ using 11-bromoundecanol (76\% yield) as alkylating agent. Following the saponification reaction with $\mathrm{KOH}$ resulted in the acid derivative in high yield. The final step in Scheme 3 was the esterification reaction to introduce the acrylate polymerizable unit using a large excess of acrylic acid in presence of $p$-toluene sulfonic acid and hydroquinone. ${ }^{21}$ The target carboxylic acid 9 was obtained in $62 \%$ yield from $i$-propanol or an aqueous ethanol solution.

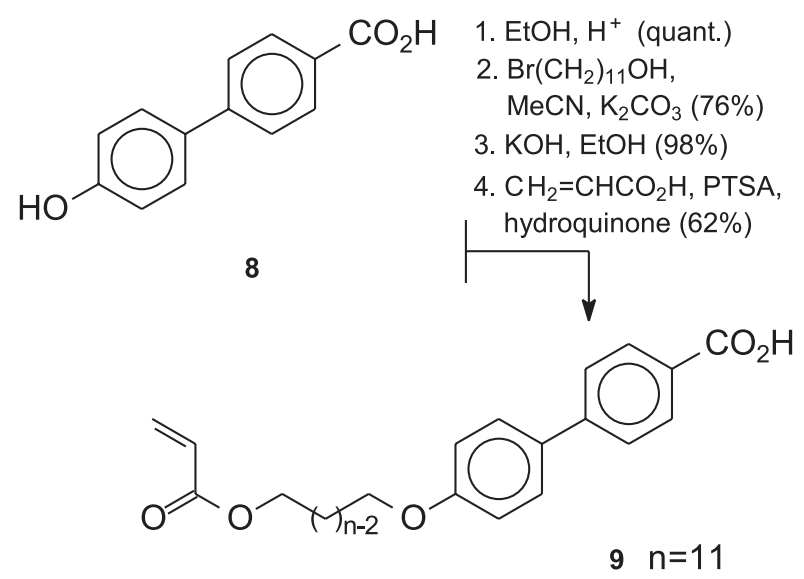

Scheme 3. Synthesis of $\mathbf{9}$.

The chiral monomers $\mathbf{1 0}$ and $\mathbf{1 1}$ were prepared as outlined in Scheme 4 following the procedures describe in reference 22. The monomers $\mathbf{1 0}$ and $\mathbf{1 1}$ were isolated and purified by silica gel column chromatography. The purified monomers were characterized by spectroscopic methods and satisfactory analytical data were obtained.

The liquid-crystalline polymers were obtained through radical polymerization. The monomers $\mathbf{1 0}$ and $\mathbf{1 1}$ were submitted to free polymerization with AIBN (5 wt \%) as the radical initiator in toluene solution to obtain the chiral polyacrylates $\mathbf{1 2}$ and $\mathbf{1 3}$. All polymerizations were carried out at $65{ }^{\circ} \mathrm{C}$ for $72 \mathrm{~h}$ under $\mathrm{N}_{2}$ inert atmosphere. Then, the polymers were precipitated into cold methanol that was filtered and purified by reprecipitation from THF solutions until no signal of ethylenic protons in NMR analysis could be observed. The polymers were obtained in $51 \%$ and $53 \%$ yield, respectively. The comparative data of the homopolymers $\mathbf{1 2}$ and $\mathbf{1 3}$ are shown in Table 1. 


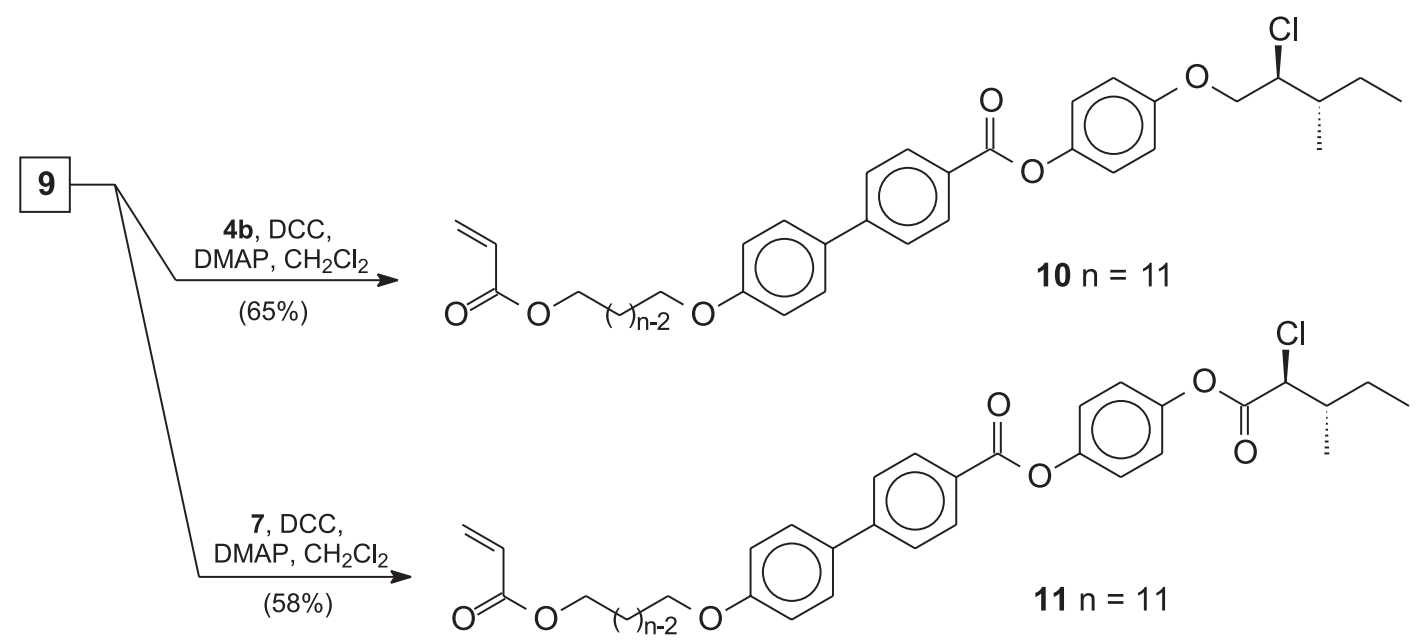

Scheme 4. Chemical synthesis of the monomers $\mathbf{1 0}$ and $\mathbf{1 1 .}$

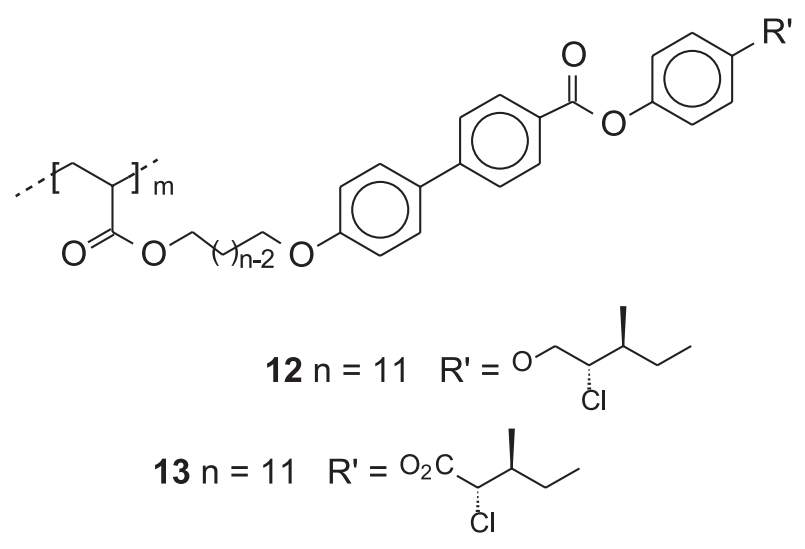

Table 1. Comparative data of the homopolymers $\mathbf{1 2}$ and $\mathbf{1 3}$

\begin{tabular}{ccccccc}
\hline Entry & Mn & Mw & PD & DP & Yield & {$[\alpha]_{D}^{20}$} \\
\hline $\mathbf{1 2}$ & 5.855 & 7.163 & 1.22 & 9 & 51 & +5 \\
$\mathbf{1 3}$ & 3.199 & 4.601 & 1.43 & 5 & 53 & +3 \\
\hline
\end{tabular}

$\mathrm{Mn}: \mathrm{g} \mathrm{mol}^{-1}$; PD: polydispersity; DP: number average degrees of polymerization; specific rotation: $1.0 \mathrm{~g}$ in $100 \mathrm{~mL} \mathrm{CH}_{2} \mathrm{Cl}_{2}$.

\section{Liquid crystals properties}

The mesomorphic properties were studied by polarization microscopy and DSC measurements and, the texture of the mesophase ${ }^{23}$ was identified by microscopy studies on cooling from the isotropic liquid state of the samples. The liquidcrystalline properties of the monomers $\mathbf{1 0}$ and $\mathbf{1 1}$ as well as polymers $\mathbf{1 2}$ and $\mathbf{1 3}$ are compiled in Table 2.

From Table 2, monomers $\mathbf{1 0}$ and $\mathbf{1 1}$ show smectic $\mathrm{C}^{*}$ and $\mathrm{A}^{*}$ phase, respectively, while the final polymers $\mathbf{1 2}$ and 13 exhibit only smectic A* phase along with a glassy state.

In the case of compound $\mathbf{1 0}$, upon cooling from the clearing point at $98^{\circ} \mathrm{C}$, a smectic phase emerges as bâtonnet at $96{ }^{\circ} \mathrm{C}$ from the isotropic liquid and finally the bâtonnets coalesce to exhibit the typical focal-conic fan-shaped indicative of a layered structure. In addition, regions of homeotropic texture are formed, a result implying that the director of the phase is orthogonal to the layer planes. Consequently, the observed phase was assigned as smectic A. Near $60{ }^{\circ} \mathrm{C}$ the sample changes slowly into a broken fan-shaped texture that, along with the simultaneous occurrence of Schlieren texture, points to a smectic $\mathrm{C}^{*}$ phase. Finally, compound $\mathbf{1 0}$ changes into crystal at $25^{\circ} \mathrm{C}$ on cooling. Also, compound $\mathbf{1 1}$ showed similar thermal behavior when compared to compound $\mathbf{1 0}$. The first liquid crystal phase of $\mathbf{1 1}$ is a smectic $A^{*}$ phase indicated by fanlike textures visible under polarized light while the second phase shows the Schlieren texture of a smectic $C^{*}$ phase. A set of the micrographs of the smectic phases is shown in Figure 2. However, the thermal stability for $\mathbf{1 1}$ is higher than $\mathbf{1 0}$. For example, $\Delta \mathrm{T}_{\mathrm{SmA}^{*} \text {-Iso }}$ is $50{ }^{\circ} \mathrm{C}$ for $\mathbf{1 1}$ and $33{ }^{\circ} \mathrm{C}$ for $\mathbf{1 0}$. The clearing point (c.p. $=\mathrm{SmA}^{*}$-Isotropic transition) of the compound $\mathbf{1 0}$ is at least $32{ }^{\circ} \mathrm{C}$ lower than 11; the enthalpy data shows the same trend from DSC studies. For example, compound 11 has $\Delta \mathrm{H}_{\text {iso }}=0.92 \mathrm{kcal} \mathrm{mol}^{-1}$ while 10 displays $\Delta \mathrm{H}_{\text {iso }}=0.48 \mathrm{kcal} \mathrm{mol}^{-1}$. It is quite clear that the thermal stability of the monomers is changed when an ester group replaces the alkoxy group at the terminal moiety; we will discuss this later.

All polymers exhibit mesophases. The polyacrylates 12 and 13 show enantiotropic SmA* phase; however, no $\mathrm{SmC}^{*}$ phase corresponding to ferroelectric LC is exhibited. The SmA*-glassy transition is seen for both polyacrylates. Polymer 12 shows the glass transition at $53{ }^{\circ} \mathrm{C}$ and melts to an isotropic liquid at $70{ }^{\circ} \mathrm{C}$. Polymer 13 enters into $\mathrm{SmA}^{*}$ phase at $40{ }^{\circ} \mathrm{C}$ during the second heating scans through the $\mathrm{SmA}^{*}$-glassy transition and it 
Table 2. Phase thermal transition of liquid crystals monomers and polymers

\begin{tabular}{|c|c|c|c|}
\hline \multirow{3}{*}{ Entry } & Phase transition temperatures $\left({ }^{\circ} \mathrm{C}\right)$ & \multirow{3}{*}{ Enthalpy Values $^{\mathrm{a}}$} & \multirow{3}{*}{$\Delta S / R^{b}$} \\
\hline & Heating & & \\
\hline & Cooling & & \\
\hline \multirow{2}{*}{10} & $\mathrm{~K} 42 \mathrm{SmC}^{*} 65 \mathrm{SmA}^{*} 98 \mathrm{I}$ & \multirow{2}{*}{$0.48 \mathrm{kcal} \mathrm{mol}^{-1}$} & \multirow{2}{*}{0.65} \\
\hline & K $25 \mathrm{SmC}^{*} 60 \mathrm{SmA} * 96 \mathrm{I}$ & & \\
\hline \multirow{2}{*}{11} & K $61 \mathrm{SmC}^{*} 80 \mathrm{SmA}^{*} 130 \mathrm{I}$ & \multirow{2}{*}{$0.92 \mathrm{kcal} \mathrm{mol}^{-1}$} & \multirow{2}{*}{1.15} \\
\hline & K $22 \mathrm{SmC}^{*} 77 \mathrm{SmA}^{*} 128 \mathrm{I}$ & & \\
\hline \multirow{2}{*}{12} & g $53 \mathrm{SmA}^{*} 70 \mathrm{I}$ & \multirow{2}{*}{$0.42 \mathrm{kcal} \mathrm{mru}^{-1}$} & \multirow{2}{*}{0.62} \\
\hline & g $45 \mathrm{SmA}^{*} 63 \mathrm{I}$ & & \\
\hline \multirow{2}{*}{13} & g $40 \mathrm{SmA}^{*} 72 \mathrm{I}$ & \multirow{2}{*}{$0.20 \mathrm{kcal} \mathrm{mru}^{-1}$} & \multirow{2}{*}{0.29} \\
\hline & g $36 \mathrm{SmA}^{*} 68 \mathrm{I}$ & & \\
\hline
\end{tabular}

${ }^{a}$ Enthalpy values were determined from isotropic phase to a liquid-crystalline $\mathrm{SmA} *$ phase at $2^{\text {nd }}$ heating stage. Scans rate: $5{ }^{\circ} \mathrm{C} \min ^{-1}$ for 10 and $11 ; 10{ }^{\circ} \mathrm{C}$ $\min ^{-1}$ for 12 and 13. $\mathrm{K}=$ crystal phase, $\mathrm{g}=$ glassy state, $\mathrm{SmC}^{*}=$ Chiral Smectic $\mathrm{C}^{*}$ phase, SmA* $=$ Chiral Smectic $\mathrm{A}^{*}$ phase; mru $=$ mol repeating unit. ${ }^{\mathrm{b}}$ Entropy changes expressed as the dimensionless quantities $\Delta \mathrm{S} / \mathrm{R} ; \mathrm{R}=8.314 \mathrm{~J} \mathrm{~mol}^{-1} \mathrm{~K}^{-1}$.

a)

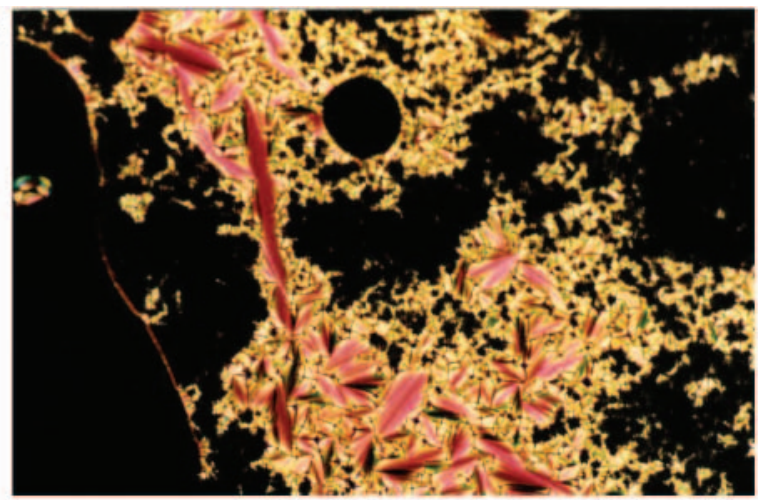

b)

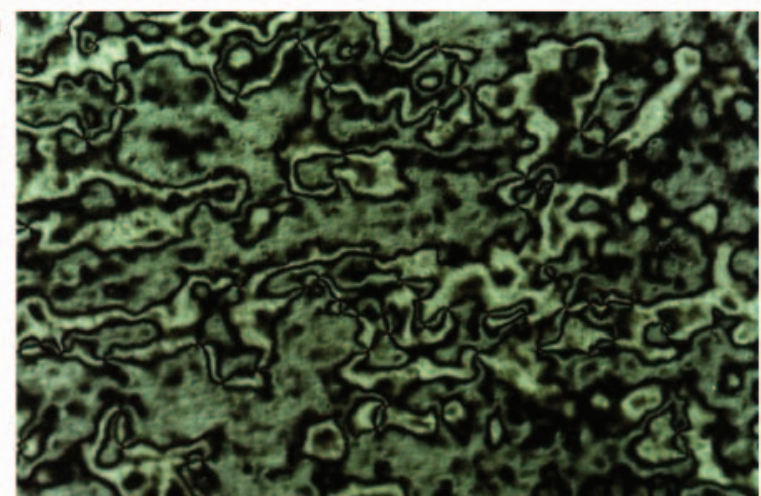

Figure 2. Polarizing optical micrographs displayed by monomer 11. (a) focal-conic fan texture and homeotropic texture of the smectic $\mathrm{A}^{*}$ phase obtained after cooling from isotropic melt to $115^{\circ} \mathrm{C}(10 \mathrm{x})$; (b) Schlieren texture of the smectic $\mathrm{C}^{*}$ phase at $72{ }^{\circ} \mathrm{C}$ obtained on cooling $(40 \mathrm{x})$. Monomer $\mathbf{1 0}$ displays the same texture of $\mathbf{1 1}$.

melts to an isotropic liquid at $72{ }^{\circ} \mathrm{C}$. The temperature ranges for the mesophase for polymers $\mathbf{1 2}$ and $\mathbf{1 3}$ are 17 ${ }^{\circ} \mathrm{C}$ and $32{ }^{\circ} \mathrm{C}$, respectively. The optical textures for these polymers which are constituted of focal conic domains remain essentially unchanged after several months. At the transition, bâtonnets develop and coalesce to form a focal- conic fan texture. Thus, we assign the phase exhibited by the polymers to smectic A* (Figure 3 ).

Here we can see again the same effect found in monomers $\mathbf{1 0}$ and $\mathbf{1 1}$, that is, the substitution of the alkoxy group by an ester group at the terminal moiety gives a more stable mesophase.

a)

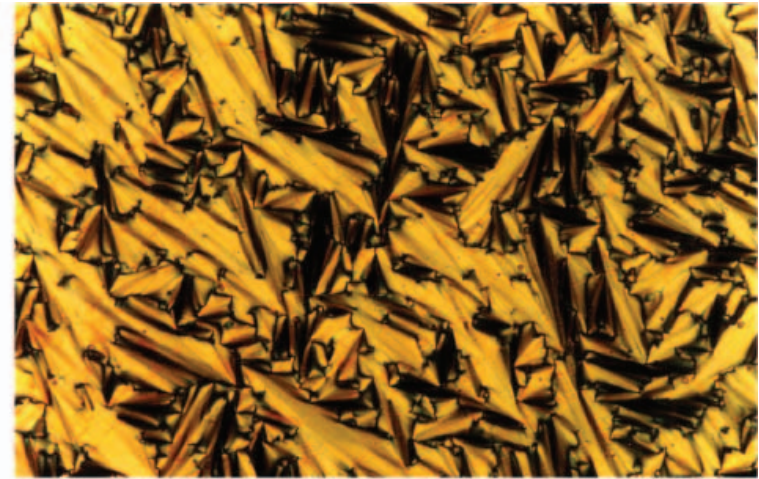

b)

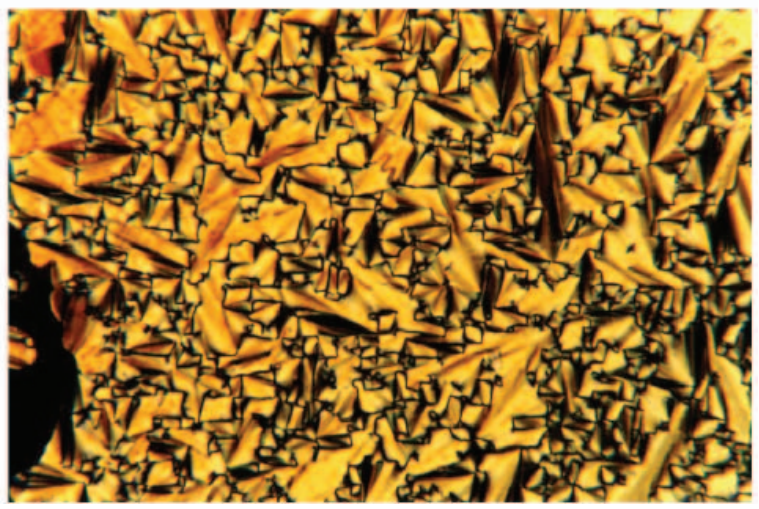

Figure 3. Polarizing optical micrographs displayed by polymers $\mathbf{1 2}$ and 13: $(a, b)$ focal-conic fan texture of the smectic $A^{*}$ phase obtained after cooling at room temperature $(40 \mathrm{x})$.

The transitional properties of monomers $\mathbf{1 0}$ and $\mathbf{1 1}$ listed in Table 2 are in agreement with general behavior 
for non polymeric liquid crystals. This behavior can be rationalized by considering the effects of the changes on chiral terminal chain while keeping the spacer and mesogenic group constant. Comparing the values at transition $\mathrm{SmA}^{*}$ to isotropic phase for compound $\mathbf{1 1}$ having the terminal ester unit with compound 10, it was shown that adding the oxygen atom to the methylene carbon atom into the ether unit gives an increase in $\Delta \mathrm{T}_{\mathrm{SmA}^{*-\mathrm{I}}}$ value of $33{ }^{\circ} \mathrm{C}$. The total range of the mesophase ( $\mathrm{SmA}^{*}$ plus $\mathrm{SmC}^{*}$ ) shows the same trend: $\Delta \mathrm{T}_{\mathrm{SmC}^{*}-\mathrm{SmA}^{*-1}}=$ $56{ }^{\circ} \mathrm{C}$ for 10 and $\Delta \mathrm{T}_{\mathrm{SmC}^{*}-\mathrm{SmA} A^{*-1}}=69^{\circ} \mathrm{C}$ for 11 . The clear conclusions to be drawn from these comparisons are that the carbonyloxy linking group is better than the oxy group in stabilizing a liquid-crystals phase. The enthalpy and entropy values corroborate this statement. The presence of the ester linking group located at the terminal chain has some effects over alkoxy terminal chain: dipole-dipole intermolecular interactions between the ester linkages are better than ether linkages; a longer and more polarizable region in the molecule is created; twisting effects are reduced; a greater planarity and better packing are observed. These effects act in synergistic manner and, therefore enhance the core-core interactions as well as alkyl chains interaction for $\mathbf{1 1}$. Hence, what it is seen here is a general manifestation of the phenomenon on smectic LC formation, i.e., the emergence of smectic properties are interrelated with microphase segregation where the aromatic cores form one domain while the alkyl chains constitute another one. This phenomenon will be more intense in polymeric liquid crystals. ${ }^{24}$

We turn our attention now to the side-chain polymers. Considering the polymeric nature of polymers $\mathbf{1 2}$ and 13 and that they do not tend to crystallize on cooling, we observe a mesophase fixation when the samples were exposed to polymerization action. From POM analysis, both polymers show a glassy appearance. The thermograms of the polymers exhibit the transition temperature $T g$ above the ambient. The vitrification ability of the polymers, i.e., to form stable glass with a glass transition temperature $T g$ above the ambient, further enhances the potential for practical applications. The glass transition temperature tends to decrease as the molecular weights decrease. The lower glass transition of polymer $\mathbf{1 3}$ implies that the backbone present in $\mathbf{1 3}$ is more flexible than in 12. The dependence of the clearing temperature on the molecular weight is also seen for polymers $\mathbf{1 2}$ and 13. The polymer $\mathbf{1 3}$ shows a clearing temperature slightly higher than polymer 12. In spite of $\Delta \mathrm{T}_{\mathrm{SmA}^{*}-\mathrm{I}}$ between 12 and 13 being very small $\left(2{ }^{\circ} \mathrm{C}\right)$, the behavior is consistent with the view that increasing backbone flexibility enhances the clearing temperature. However, as discussed previously for monomers $\mathbf{1 0}$ and $\mathbf{1 1}$, the chiral terminal chain is not the same in the final polymers. So, we expect that the transitional properties are not determined solely by polymer backbone, but also by a dependence on electronic and conformational effects present in a chiral terminal chain. Its influence will be transmitted to the rest of the molecule contributing to their transitional properties.

It will be helpful to relate the transitional data of the polymer LC with the internal structural arrangement of the smectic $\mathrm{A}^{*}$ phase observed for polymers like $\mathbf{1 2}$ and 13. If we consider that the backbone is in an isotropic arrangement but not confined by the smectic field and lies between the layers, ${ }^{25}$ two arrangements are possible. In one arrangement the side chains are more tighted than in the other causing a partially interdigitated phase, termed $\mathrm{S}_{\mathrm{Ad}}$. In the other arrangement, termed $\mathrm{S}_{\mathrm{A} 2}$, the side chains exhibit no interdigitation. The evidence of this classification comes from other data published in the literature. ${ }^{26}$

Using only thermal and entropic data listed in Table 2 , it is not safety to distinguish clearly these two structures. At this point we can not get a more precise description of this behavior and X-ray experiments should be addressed.

The $T g$ values observed for these polymers could be related to the specific free volume of the mesophase. The relationship between phase structure and glass transition temperature is dominated by packing density of the mesophase. ${ }^{27} \mathrm{We}$ expect a higher glass transition temperature for polymers which exhibit smectic phases than for nematic phase ones. Hence, there is a reduction in the specific free volume in the smectic phase when compared with the nematic phase. ${ }^{10,11}$ In $\mathrm{SmA}^{*}$ environment, there is a partial overlapping of the side chains which contribute to reduction of specific free volume, increasing the $T g$.

\section{Conclusions}

In this work two new chiral side-chain liquidcrystalline polyacrylates $\mathbf{1 2}$ and $\mathbf{1 3}$ were synthesized by introducing a chlorine-containing chiral LC group onto the side chains. The mesomorphic behavior of the polymers as well as of the monomers $\mathbf{1 0}$ and $\mathbf{1 1}$ were investigated using POM and DSC techniques. Both polymers showed enantiotropic $\mathrm{SmA}^{*}$ phase while the corresponding monomers showed both $\mathrm{SmC}^{*}$ and $\mathrm{SmA}^{*}$ phases. For the monomers, the conclusions to be drawn are that the carbonyloxy linking group is superior to the oxy group in stabilizing a liquid-crystals phase. Polymers 12 and 13 exhibit a glass transition above room 
temperature. Mesophase fixation occurs through the glassy matrix, which "freezes" the focal-conic texture for a long time. The thermal properties of polyacrylates are dependent on the structural and electronic parameters as well as on the molecular weight. Based on DSC data we have shown that polymer $\mathbf{1 3}$ exhibits a decrease of glass transition, but a clearing temperature higher than $\mathbf{1 2}$.

\section{Experimental}

\section{Materials}

L-Isoleucine, $p$-hydroxy methylbenzoate, 4- $(N, N$ dimethylamino)pyridine (DMAP), 1,3-dicyclohexylcarbodiimide (DCC), 2,2'-azobis(isobutyronitrile) $(\mathrm{AIBN})$, diethylazodicarboxilate (DEAD) and triphenylphosphine $\left(\mathrm{PPh}_{3}\right)$ were purchased from Aldrich and used as received unless otherwise specified. Dichloromethane $\left(\mathrm{CH}_{2} \mathrm{Cl}_{2}\right)$ was distilled over calcium hydride $\left(\mathrm{CaH}_{2}\right)$ under argon immediately before use. Analytical thin-layer chromatography (TLC) was conducted on Merck aluminum plates with $0.2 \mathrm{~mm}$ of silica gel 60F-254. Anhydrous sodium sulfate was used to dry all organic extracts. Toluene was first refluxed over sodium and then distilled under argon. AIBN was freshly recrystallized from methanol. Purification by column chromatography was carried out on 70-230 mesh Merck silica gel 60 and hexane, ethyl acetate and dichloromethane (DCM) as eluent.

\section{Characterization}

${ }^{1} \mathrm{H}$ NMR and ${ }^{13} \mathrm{C}$ NMR spectra were obtained in $\mathrm{CDCl}_{3}$ with Varian-200 and $300 \mathrm{MHz}$ spectrometers, using TMS as the internal standard. IR Spectra were recorded in $\mathrm{KBr}$ discs, nujol dispersions or film with a 3000 Galaxy Series Spectrometer. Elemental analysis was measured on Perkin Elmer 2400CHN. Optical rotations were recorded on a Perkin-Elmer 341 polarimeter at the sodium D line. CG analysis was conducted in a Varian 2 equipped with FID detector using $\mathrm{H}_{2}$ as carrier gas.

\section{Thermal characterization}

The thermal transitions and the mesomorphic textures were taken using a Olympus BX41 polarizing microscope in conjunction with a Leitz Wetzlar 417 heating stage and Perkin Elmer DSC4 differential scanning calorimeter. The rate of heating or cooling was $5^{\circ} \mathrm{C} \mathrm{min}-1$ for the monomers 10 and 11 and $10{ }^{\circ} \mathrm{C} \mathrm{min}-1$ for polymers 12 and 13 Molecular weights reported in Table 1 are relative to polystyrene standards and they have been characterized by using Waters GPC systems (Waters 150C refractomer).

(2S,3S)-(+)-2-Chloro-3-methylpentanoic acid (2) and (2S,3S)-(+)-2-chloro-3-methyl-1-pentanol (3). Compounds $\mathbf{2}$ and $\mathbf{3}$ were prepared according to conditions described by Koppenhoefer and Schurig. ${ }^{12}$ Data for compound 2: colorless oil $(67 \%) ;[\alpha]_{D}^{20}=-1.44$ (neat). ${ }^{1} \mathrm{H}$ NMR $\left(\mathrm{CDCl}_{3}, 300 \mathrm{MHz}\right) \delta 0.93\left(\mathrm{t}, 3 \mathrm{H}, \mathrm{CH}_{3}\right) ; 1.06$ $\left(\mathrm{d}, 3 \mathrm{H}, \mathrm{CH}_{3}\right) ; 1.25\left(\mathrm{~m}, 1 \mathrm{H}, \mathrm{CH}_{2} \mathrm{CH}_{3}\right) ; 1.62(\mathrm{~m}, 1 \mathrm{H}$, $\left.\mathrm{CH}_{2} \mathrm{CH}_{3}\right) ; 2.15\left(\mathrm{~m}, 1 \mathrm{H}, \mathrm{CHCH}_{3}\right) ; 4.24(\mathrm{~d}, 1 \mathrm{H}, \mathrm{C} \underline{\mathrm{HCl}}, J$ $6.34 \mathrm{~Hz}) ; 9.60\left(\mathrm{br}, 1 \mathrm{H}, \mathrm{CO}_{2} \mathrm{H}\right) .{ }^{13} \mathrm{C} \mathrm{NMR}\left(\mathrm{CDCl}_{3}, 50\right.$ $\mathrm{MHz}) \delta 10.8 ; 15.8 ; 24.8 ; 38.7 ; 62.7 ; 175.2$. Data for compound 3: colorless oil $(57 \%) ;[\alpha]_{D}^{20}=-6.70$ (neat). IR (nujol) $v_{\max } / \mathrm{cm}^{-1}: 3373 ; 2966 ; 2878 ; 1460 ; 1381 ; 1075$; $1032 ; 814 ; 773 ;{ }^{1} \mathrm{H}$ NMR $\left(\mathrm{CDCl}_{3}, 200 \mathrm{MHz}\right) d 0.92(\mathrm{t}$, $\left.3 \mathrm{H}, \mathrm{CH}_{3}, J 7.40 \mathrm{~Hz}\right) ; 1.01$ (d, 3H, $\left.\mathrm{CH}_{3}, J 6.82 \mathrm{~Hz}\right) ; 1.25$ $\left(\mathrm{m}, 1 \mathrm{H}, \mathrm{CH}_{\mathrm{HCH}}\right) ; 1.50\left(\mathrm{~m}, 1 \mathrm{H}, \mathrm{CH}^{2} \mathrm{HCH}_{3}\right) ; 1.80(\mathrm{~m}$, $\left.1 \mathrm{H}, \mathrm{CHCH}_{3}\right) ; 2.20$ (m, OH, br); $3.66(\mathrm{dd}, 1 \mathrm{H}, \mathrm{C} \underline{\mathrm{H} H \mathrm{H}}$, $\left.{ }^{2} J_{\text {gem }} 12.10,{ }^{3} J_{\text {trans }} 7.74 \mathrm{~Hz}\right) ; 3.77\left(\mathrm{dd}, 1 \mathrm{H}, \mathrm{CH} \underline{\mathrm{HOH}},{ }^{2} J_{\text {gem }}\right.$ $12.10,{ }^{3} J_{\text {cis }} 3.64 \mathrm{~Hz}$ ); 3.91 (ddd, $1 \mathrm{H}, \mathrm{CHCl}^{3}{ }^{3}{ }_{\text {trans }} 7.70 \mathrm{~Hz}$, $\left.{ }^{3} J_{\text {trans }} 5.62,{ }^{3} J_{\text {cis }} 3.60 \mathrm{~Hz}\right) ;{ }^{13} \mathrm{C} \mathrm{NMR}\left(\mathrm{CDCl}_{3}, 50 \mathrm{MHz}\right) d$ $10.9 ; 15.6 ; 24.7 ; 37.8 ; 64.4 ; 69.8$.

$(2 S, 3 S)-(+)-4-[(2-C h l o r o-3-m e t h y l) p e n t y l o x y] p h e n y l$ benzoate (4a). This compound was synthesized according to reference 11 . Physical and spectroscopic data: white solid (52\%); $[\alpha]_{D}^{20}=+13\left(1.0 ; \mathrm{CH}_{2} \mathrm{Cl}_{2}\right)$; Anal. calc. for $4 \mathbf{a}$ $\mathrm{C}_{19} \mathrm{H}_{21} \mathrm{O}_{3} \mathrm{Cl}\left(332.5 \mathrm{~g} \mathrm{~mol}^{-1}\right): \mathrm{C}, 68.67 ; \mathrm{H}, 6.32$; found: $\mathrm{C}$, 68.48; H, 6.28; ${ }^{1} \mathrm{H}$ NMR $\left(\mathrm{CDCl}_{3}, 200 \mathrm{MHz}\right) \delta 0.88(\mathrm{t}$, $3 \mathrm{H}, \mathrm{CH}_{3}, J 7.40 \mathrm{~Hz}$ ); 1.01 (d, 3H, $\left.\mathrm{CH}_{3}, J 6.82 \mathrm{~Hz}\right) ; 2.25$ $\left(\mathrm{m}, 1 \mathrm{H}, \mathrm{CHHCH}_{3}\right) ; 2.55\left(\mathrm{~m}, 1 \mathrm{H}, \mathrm{CH}^{\mathrm{HCH}}{ }_{3}\right) ; 1.95(\mathrm{~m}, 1 \mathrm{H}$, $\left.\mathrm{C}_{\underline{H}} \mathrm{H}_{3}\right) ; 4.15$ (m, 3H, $\left.\underline{\mathrm{H}}_{2} \mathrm{O}, \mathrm{C} \underline{\mathrm{HCl}}\right) ; 6.94$ (d, 2H, Ar, J $8.96 \mathrm{~Hz}$ ); 7.12 (d, 2H, Ar, J 9.10 Hz); 7.50 (m, 2H, Ar); $7.60(\mathrm{~m}, 1 \mathrm{H}, \mathrm{Ar}) ; 8.20(\mathrm{~d}, 2 \mathrm{H}, \mathrm{Ar}) ;{ }^{13} \mathrm{C} \mathrm{NMR}\left(\mathrm{CDCl}_{3}\right.$, 50MHz) $\delta 11.5 ; 16.1 ; 24.5 ; 38.1 ; 64.8 ; 70.3 ; 115.4 ; 122.5$; $128.5 ; 129.5 ; 130.1 ; 133.5 ; 144.8 ; 156.0 ; 165.4 ; \mathrm{CG} / \mathrm{MS}$ (EI, $70 \mathrm{eV}): 334\left(\mathrm{M}^{+}+2,3 \%\right) ; 332\left(\mathrm{M}^{+}, 9 \%\right) ; 214(3 \%)$; 105 (100\%); 77 (51\%); 51 (17\%); 41 (16\%).

(2S,3S)-(+)-4-[(2-Chloro-3-methyl)pentyloxy]phenol (4b). To $2.0 \mathrm{mmol}$ of $(2 S, 3 S)-(+)-4-[(2-$ chloro-3-methyl)pentyloxy]phenyl benzoate $(\mathbf{4 a})$ in the mixture ethanol/ water $(15 \mathrm{~mL}), 2.4 \mathrm{mmol}$ of potassium hydroxide was added. The mixture was stirred overnight at room temperature. The ethanol was evaporated and the product was extracted from diethyl ether and washed with water $(2 \times 25 \mathrm{~mL})$ and dried over $\mathrm{Na}_{2} \mathrm{SO}_{4}$ and purified on silica gel using ethyl acetate/hexane (1:9) to yield $\mathbf{4 b}(74 \%)$. mp $60{ }^{\circ} \mathrm{C}$ (ethanol); $[\alpha]_{D}^{20}=+16\left(1.0 ; \mathrm{CH}_{2} \mathrm{Cl}_{2}\right) ; \mathrm{IR}$ (nujol) $v_{\max } / \mathrm{cm}^{-1}: 3363 ; 2965 ; 2877 ; 1604 ; 1455 ; 1511 ; 1229 ;{ }^{1} \mathrm{H}$ 
NMR $\left(\mathrm{CDCl}_{3}, 200 \mathrm{MHz}\right) \delta 0.87$ (t, 3H, $\left.\mathrm{CH}_{3}, J 7.40 \mathrm{~Hz}\right)$; $0.99\left(\mathrm{~d}, 3 \mathrm{H}, \mathrm{CH}_{3}, J 6.82 \mathrm{~Hz}\right) ; 1.50\left(\mathrm{~m}, 1 \mathrm{H}, \mathrm{C}_{\mathbf{H H C H}}\right)$; $1.90\left(\mathrm{~m}, 1 \mathrm{H}, \underline{\mathrm{CHHCH}}_{3}\right) ; 4.02$ (m, 3H, OC$\left.\underline{\mathrm{H}}_{2}, \mathrm{C} \underline{\mathrm{HCl}}\right) ; 5,10$ (br, $1 \mathrm{H}, \mathrm{OH}) ; 6.70(\mathrm{~m}, 4 \mathrm{H}, \mathrm{Ar}) ;{ }^{13} \mathrm{C}$ NMR $\left(\mathrm{CDCl}_{3}, 50\right.$ MHz) $\delta 11.5 ; 16.1 ; 24.5 ; 38.1 ; 65.2 ; 70.8 ; 116.1 ; 116.2$; 150.0; 152.5; CG/MS (EI, $70 \mathrm{eV}): 230\left(\mathrm{M}^{+}+2,5 \%\right) ; 228$ $\left(\mathrm{M}^{+}, 15 \%\right) ; 123$ (3\%); 110 (100\%); 93 (5\%); 81 (22\%); 65 (13\%); 55 (29\%); 41 (33\%).

4-Hydroxyphenyl benzoate (6). Compound 6 was synthesized following the procedure reported by Svensson et al. ${ }^{18}$ Data: yield (63\%); mp $172{ }^{\circ} \mathrm{C}$. IR $v_{\max } / \mathrm{cm}^{-1}: 3368$; 2928; 1515; 1463; 1377; 1242; 1105; 770; 722; ${ }^{1} \mathrm{H}$ NMR ( $\left.\mathrm{CDCl}_{3} / \mathrm{DMSO}, 200 \mathrm{MHz}\right): \delta 6.90$ (dd, 4H, Ar); 7.52 (m, $3 \mathrm{H}, \mathrm{Ar}) ; 8.10$ (d, 2H, Ar).

$(2 S, 3 S)-(+)-4-[(2-C h l o r o-3-m e t h y l) p e n t a n o y l o x y] p h e n o l$ (7). To a solution of the acid $2(7 \mathrm{mmol})$ in dichloromethane-DCM $(5 \mathrm{~mL})$ thionyl chloride $(5 \mathrm{~mL})$ was added under a dry nitrogen atmosphere. The solution obtained was stirred for $24 \mathrm{~h}$ at room temperature. The excess of $\mathrm{SOCl}_{2}$ and the solvent were removed and the residue oil was dissolved in dry DCM and used without further purification. 1,4-dihydroxybenzene (14 mmol) and DMAP $(10 \mathrm{mg})$ were dissolved in a mixture of 5 $\mathrm{mL}$ of pyridine and $10 \mathrm{~mL}$ of dry DCM and the final solution was cooled to $5{ }^{\circ} \mathrm{C}$ in an ice bath. The solution of the acid chloride in DCM previously prepared was added drop-wise via syringe under vigorous stirring. The reaction mixture was stirred for $48 \mathrm{~h}$ at room temperature. The mixture of solvent was removed under reduced pressure with the temperature kept below $35{ }^{\circ} \mathrm{C}$. The crude product was subjected to column chromatography (eluent DCM). After evaporation of eluent the solid residue was recrystallized twice from ethanol result in $\mathbf{7}$ $(35 \%)$ as a viscous oil. $[\alpha]{ }_{D}^{20}=+4\left(1.0 ; \mathrm{CH}_{2} \mathrm{Cl}_{2}\right) ;{ }^{1} \mathrm{H}$ NMR $\left(\mathrm{CDCl}_{3}, 200 \mathrm{MHz}\right) \delta 0.92\left(\mathrm{t}, 3 \mathrm{H}, \mathrm{CH}_{3}, J 7.4 \mathrm{~Hz}\right)$; $1.10\left(\mathrm{~d}, 3 \mathrm{H}, \mathrm{CH}_{3}, J 6.6 \mathrm{~Hz}\right) ; 1.40\left(\mathrm{~m}, 1 \mathrm{H}, \mathrm{CHHCH}_{3}\right)$; $\left.1.75\left(\mathrm{~m}, 1 \mathrm{H}, \mathrm{CH}^{\mathrm{HCH}}\right)_{3}\right) ; 2.20\left(\mathrm{~m}, 1 \mathrm{H}, \mathrm{CHCH}_{3}\right) ; 4.36(\mathrm{~d}$, $1 \mathrm{H}, \mathrm{C} \underline{\mathrm{HCl}}, J 7.0 \mathrm{~Hz}) ; 6.70$ (d, 2H, Ar, J 9.0 Hz); 7.10 (d, $2 \mathrm{H}, \mathrm{Ar}, J 9.0 \mathrm{~Hz}$ ).

4'-[(11-Acryloyloxy)undecyloxy)]biphenyl-4-carboxylic acid (9). Compound 9 was synthesized according to references 19, 20 and 21 (46\% for 4 steps). White solid; mp $220{ }^{\circ} \mathrm{C}$ (isopropanol); IR (KBr) $v_{\text {max }} / \mathrm{cm}^{-1}: 3080-2700$; 2929; 2853; 1718; 1685; 1605; 1464; 1250; 1177; 1037; 854; 772; ${ }^{1} \mathrm{H}$ NMR $\left(\mathrm{CDCl}_{3} / \mathrm{DMSO}, 200 \mathrm{MHz}\right) \delta 1.4(\mathrm{~m}$, $\left.14 \mathrm{H},\left(\mathrm{CH}_{2}\right)_{7}\right) ; 1.65\left(\mathrm{~m}, 2 \mathrm{H}, \mathrm{CH}_{2}\right) ; 1.85\left(\mathrm{~m}, 2 \mathrm{H}, \mathrm{CH}_{2}\right) ; 4.01$ (t, $\left.2 \mathrm{H}, \mathrm{CH}_{2} \mathrm{O}\right) ; 4.13\left(\mathrm{t}, 2 \mathrm{H}, \mathrm{CH}_{2} \mathrm{O}\right) ; 5.83\left(\mathrm{dd}, 1 \mathrm{H}, \mathrm{CH}=\mathrm{CH}_{2}\right.$, $\left.{ }^{3} J_{\text {cis }} 10.2 \mathrm{~Hz},{ }^{2} J_{\text {gem }} 1.6 \mathrm{~Hz}\right) ; 6.13\left(\mathrm{dd}, 1 \mathrm{H}, \mathrm{CH}=\mathrm{CH}_{2},{ }^{3} J_{\text {cis }}\right.$ $\left.10.4 \mathrm{~Hz},{ }^{3} J_{\text {trans }} 17.2 \mathrm{~Hz}\right) ; 6.40\left(\mathrm{dd}, 1 \mathrm{H}, \mathrm{CH}=\mathrm{CH}_{2},{ }^{3} \mathrm{~J}_{\text {trans }} 17.2\right.$ $\left.\mathrm{Hz},{ }^{2} J_{\text {gem }} 1.8 \mathrm{~Hz}\right) ; 6.99$ (d, 2H, Ar, J $\left.8.8 \mathrm{~Hz}\right) ; 7.58(\mathrm{~d}, 2 \mathrm{H}$, Ar, $J 8.8 \mathrm{~Hz}) ; 7.63$ (d, 2H, Ar, J $8.4 \mathrm{~Hz}) ; 8.09$ (d, 2H, Ar, $J$ 8.4 Hz); ${ }^{13} \mathrm{C} \mathrm{NMR}\left(\mathrm{CDCl}_{3}, 50 \mathrm{MHz}\right) d 25.4 ; 25.5 ; 28.1$; $28.7 ; 28.8 ; 28.9 ; 64.1 ; 67.1 ; 67.6 ; 114.4 ; 125.7 ; 127.7$; $128.1 ; 128.4 ; 129.8 ; 130.0 ; 131.6 ; 144.4 ; 158.8 ; 167.9$.

(2S,3S)-(+)-4-[(2-Chloro-3-methyl)pentyloxy]phenyl 4'[11-(acryloxy)undecyloxy]biphenyl-4-carboxylate (10). Monomers $\mathbf{1 0}$ and $\mathbf{1 1}$ were synthesized according to reference 22. $(2 S, 3 S)-(+)-4-[(2-$ chloro-3-methyl)pentyloxy]phenol (4b) $(0.20 \mathrm{~g}, 0.87 \mathrm{mmol})$ and $4^{\prime}-[(11-$ acryloyloxy)undecyloxy)]biphenyl-4-carboxylic acid (9) $(0.38 \mathrm{~g}, 0.87 \mathrm{mmol})$ were added in dry $\mathrm{CH}_{2} \mathrm{Cl}_{2}(15 \mathrm{~mL})$ under argon and the solution was stirred at room temperature for $10 \mathrm{~min}$. Then, 1,3-dicyclohexylcarbodiimide (DCC) $(0.19 \mathrm{~g}, 0.97 \mathrm{mmol})$ and $4-(\mathrm{N}, \mathrm{N}$ dimethylamino)pyridine (DMAP) $(10 \mathrm{mg})$ were added. The solution was stirred for $24 \mathrm{~h}$ at room temperature. The solution was filtered and the solvent evaporated. The crude product was purified by column chromatography ( silica gel, diethyl ether/hexane $=1: 9)$ to yield $(0.36 \mathrm{~g}$, $65 \%) \mathbf{1 0}$ as white solid. $[\alpha]_{D}^{20}=+3.0\left(1.0 ; \mathrm{CH}_{2} \mathrm{Cl}_{2}\right)$; Anal. calc. for $10 \mathrm{C}_{39} \mathrm{H}_{49} \mathrm{O}_{6} \mathrm{Cl}\left(648.5 \mathrm{~g} \mathrm{~mol}^{-1}\right)$ : C 71.84; $\mathrm{H} 7.35$; found: C 72.16; H 7.55; IR (nujol) $v_{\max } / \mathrm{cm}^{-1}: 2923 ; 2859$; $1729 ; 1607 ; 1511 ; 1462 ; 1377 ; 1259 ; 1192 ; 1165 ; 1057$; 795; 716; ${ }^{\mathrm{H}} \mathrm{NMR}\left(\mathrm{CDCl}_{3}, 200 \mathrm{MHz}\right) \delta 0.96\left(\mathrm{t}, 3 \mathrm{H}, \mathrm{CH}_{3}\right.$, $J 7.40 \mathrm{~Hz}) ; 1.08\left(\mathrm{~d}, 3 \mathrm{H}, \mathrm{CH}_{3}, J 6.60 \mathrm{~Hz}\right) ; 1.35(\mathrm{~m}, 18 \mathrm{H}$, $\left.\left(\mathrm{CH}_{2}\right)_{9}\right) ; 1.65\left(\mathrm{~m}, 1 \mathrm{H}, \mathrm{CHHCH}_{3}\right) ; 1.80\left(\mathrm{~m}, 1 \mathrm{H}, \mathrm{CHHCH}_{3}\right)$; $2.00\left(\mathrm{~m}, 1 \mathrm{H}, \mathrm{CHCH}_{3}\right) ; 4.11\left(\mathrm{t}, 2 \mathrm{H}, \mathrm{CH}_{2} \mathrm{O}, J 6.3 \mathrm{~Hz}\right) ; 4.18$ $\left(\mathrm{m}, 5 \mathrm{H}, \mathrm{CH}_{2} \mathrm{O}, \mathrm{C} \underline{\mathrm{HCl}}\right) ; 5.80\left(\mathrm{dd}, 1 \mathrm{H}, \mathrm{CH}=\mathrm{CH}_{2},{ }^{3} J_{\text {cis }} 10.2\right.$ $\left.\mathrm{Hz},{ }^{2} J_{\text {gem }} 1.8 \mathrm{~Hz}\right) ; 6.11\left(\mathrm{dd}, 1 \mathrm{H}, \mathrm{CH}=\mathrm{CH}_{2},{ }^{3} J_{\text {cis }} 10.4 \mathrm{~Hz}\right.$, $\left.{ }^{3} J_{\text {trans }} 17.2 \mathrm{~Hz}\right) ; 6.40\left(\mathrm{dd}, 1 \mathrm{H}, \mathrm{CH}=\mathrm{CH}_{2},{ }^{3} J_{\text {trans }} 17.2 \mathrm{~Hz},{ }^{2} J_{\text {gem }}\right.$ $1.8 \mathrm{~Hz}) ; 6.95$ (d, 2H, Ar, J 9.0 Hz); 7.02 (d, 2H, Ar, J 8.4 $\mathrm{Hz}$ ); 7.14 (d, 2H, Ar, J 9.2 Hz); 7.59 ( d, 2H, Ar, $J 8.8$ $\mathrm{Hz}$ ); 7.68 (d, 2H, Ar, J 8.6 Hz); 8.22 (d, 2H, Ar, J $8.6 \mathrm{~Hz}$ ); ${ }^{13} \mathrm{C}$ NMR $\left(\mathrm{CDCl}_{3}, 50 \mathrm{MHz}\right) \delta 11.5 ; 16.0 ; 24.4 ; 25.8 ; 26.0$; $28.6 ; 29.2 ; 29.3 ; 29.4 ; 29.7 ; 38.0 ; 64.7 ; 64.8 ; 68.1 ; 70.2$; $114.9 ; 115.3 ; 115.4 ; 122.6 ; 126.5 ; 127.4 ; 128.2 ; 128.3$; $128.5 ; 130.5 ; 130.6 ; 131.8 ; 144.8 ; 145.8 ; 155.9 ; 159.5$; $165.4 ; 166.32$.

(2S,3S)-(+)-4-[(2-Chloro-3-methyl)pentanoyloxy]phenyl 4'-[11-(acryloxy)undecyloxy]biphenyl-4-carboxylate (11). This compound was synthesized according to the procedure described above. Physical and spectroscopic data: Yield: $(0.32 \mathrm{~g}, 58 \%)$ after column chromatography ( silica gel, diethyl ether/hexane $=1: 9$ ) as white solid. $[\alpha]_{D}^{20}=+2.0\left(1.0 ; \mathrm{CH}_{2} \mathrm{Cl}_{2}\right)$; Anal. calc. for $11 \mathrm{C}_{39} \mathrm{H}_{47} \mathrm{O}_{7} \mathrm{Cl}$ (662.5 $\mathrm{g} \mathrm{mol}^{-1}$ ): C 70.64; H 7.10; found: C 69.95; H 7.40; IR (nujol) $v_{\max } / \mathrm{cm}^{-1}: 2923 ; 2854 ; 1725 ; 1605 ; 1511 ; 1462$; 
1377; 1279; 1195; 1070; 963; ${ }^{\mathrm{H}} \mathrm{NMR}\left(\mathrm{CDCl}_{3}, 200 \mathrm{MHz}\right)$ $\delta 1.00\left(\mathrm{t}, 3 \mathrm{H}, \mathrm{CH}_{3}, J 6.80 \mathrm{~Hz}\right) ; 1.13\left(\mathrm{~d}, 3 \mathrm{H}, \mathrm{CH}_{3}, J 6.60\right.$ $\mathrm{Hz}) ; 1.38\left(\mathrm{~m}, 18 \mathrm{H},\left(\mathrm{CH}_{2}\right)_{9}\right) ; 1.77$ (m, 2H, $\left.\underline{\mathrm{HHCH}}_{3}\right) ; 2.25$ $\left(\mathrm{m}, 1 \mathrm{H}, \mathrm{CHCH}_{3}\right) ; 4.00$ (t, $\left.2 \mathrm{H}, \mathrm{CH}_{2}, J 6.4 \mathrm{~Hz}\right) ; 4.15(\mathrm{t}, 2 \mathrm{H}$, $\left.\mathrm{CH}_{2} \mathrm{O}, J 6.5 \mathrm{~Hz}\right) ; 4.39$ (d, 1H, CHCl, $\left.J 7 \mathrm{~Hz}\right) ; 5.80(\mathrm{dd}$, $\left.1 \mathrm{H}, \mathrm{CH}=\mathrm{CH}_{2},{ }^{3} J_{\text {cis }} 10.2 \mathrm{~Hz},{ }^{2} J_{\text {gem }} 1.8 \mathrm{~Hz}\right) ; 6.11(\mathrm{dd}, 1 \mathrm{H}$, $\left.\mathrm{CH}=\mathrm{CH}_{2},{ }^{3} J_{\text {cis }} 10.4 \mathrm{~Hz},{ }^{3} J_{\text {trans }} 17.2 \mathrm{~Hz}\right) ; 6.40(\mathrm{dd}, 1 \mathrm{H}$, $\left.\mathrm{CH}=\mathrm{CH}_{2},{ }^{3} J_{\text {trans }} 17.2 \mathrm{~Hz},{ }^{2} J_{\text {gem }} 1.8 \mathrm{~Hz}\right) ; 6.99(\mathrm{~d}, 2 \mathrm{H}, \mathrm{Ar}, J$ $8.8 \mathrm{~Hz}$ ); 7.18 (d, 2H, Ar, J 9.2 Hz); 7.27 (d, 2H, Ar, J 9.2 $\mathrm{Hz}) ; 7.64$ (d, 2H, Ar, J 8.8 Hz); 7.68 (d, 2H, Ar, J 8.4 Hz); $8.22(\mathrm{~d}, 2 \mathrm{H}, \mathrm{Ar}, J 8.6 \mathrm{~Hz}) ;{ }^{13} \mathrm{C} \mathrm{NMR}\left(\mathrm{CDCl}_{3}, 50 \mathrm{MHz}\right) \delta$ $11.0 ; 15.9 ; 25.1 ; 25.8 ; 26.0 ; 28.6 ; 29.2 ; 29.3 ; 29.5 ; 39.0$; $62.5 ; 64.6 ; 68.1 ; 114.9 ; 122.1 ; 122.7 ; 126.5 ; 127.0 ; 128.3$; $128.5 ; 130.4 ; 130.6 ; 131.7 ; 146.0 ; 147.6 ; 148.6 ; 159.5$; $164.8 ; 166.3 ; 167.7$.

\section{Polymerization}

All the polymerization reactions were carried out in toluene solution at $65^{\circ} \mathrm{C}$ using the initiator 2,2'azobisisobutyronitrile, AIBN, (5\% wt). The yields were 50$60 \%$ based on total monomer added to the reaction. All reactions were refluxed for 72 hours and, after cooling, were precipitated from cold methanol. The precipitates were purified by successively re-precipitation in cold methanol from toluene solution and dried in vacuum. The purity of homopolymers was checked by ${ }^{1} \mathrm{H}$ NMR. The data are for polymer 12: Yield $(51 \%) ;[\alpha]_{D}^{20}+5.0\left(1.0 ; \mathrm{CH}_{2} \mathrm{Cl}_{2}\right)$ and polymer 13: Yield (53\%); $[\alpha]_{D}^{20}+3.0\left(1.0 ; \mathrm{CH}_{2} \mathrm{Cl}_{2}\right)$.

\section{Acknowledgments}

This research was supported by CNPq agency through Edital Universal 2001. O.M.S.R thanks CNPq agency for her fellowship. The authors thanks Prof. Cesar L. Petzhold for helpfull discussions.

\section{Supplementary Information}

Supplementary data are available free of charge as PDF file at http://jbcs.sbq.org.br.

\section{References}

1. Reinitzer, R.; Monatsh. Chem. 1888, 9, 421.

2. Schadt, M.; Helfrich, W. Appl. Phys. Lett. 1971, 18, 127.

3. Fergason, J.; US pat. 3918796, 1971.
4. MacArdle, C. B.; Side-Chain Liquid Crystal Polymers, Blackie Academic and Professional: London, 1989.

5. Shibaev, V. P.; Platé, N. A.; Freidzon, Y. S.; J. Polym. Sci., Part A: Polym. Chem. 1979, 17, 1665; Finkelmann, H.; Ringsdorf, H.;Wendorff, J. H. Makromolekulare Chemie-Macromolecular Chemistry and Physics 1978, 179, 273.

6. Shibaev, V. P.; Platé, N. A.; Kozlovsky, M. V.; Beresnev, L. A.; Blinov, L. M. Polym. Bull., 1984, 12, 299.

7. Kaempf, G.; Polym. J. 1987, 19, 257.

8. Kocot, A.; Wrzalik, R.; Vij, J. K.; Zentel, R. J. J. Appl. Phys. 1994, 75, 728.

9. Ciferri, A.; Liquid Crystallinity in Polymers, Chapman and Hall: New York, 1991.

10. Merlo, A. A.; Ritter, O. M. S.; Pereira, F. V.; Vieira, C. H.; da Silveira, N. P.; J. Braz. Chem. Soc. 2001, 12, 184.

11. Ritter, O. M. S.; Merlo, A. A.; Pereira, F. V.; da Silveira, N. P.; Geissler, E.; Zukerman-Schpector, J. Liq. Cryst. 2002, 29, 1187.

12. Koppenhoefer, B.; Schurig, V.; Org. Synthesis, 1987, 66, 151.

13. Carey, F. A.; Sundberg, R. J.; Advanced Organic Chemistry, $3^{\text {th }}$ ed.; part B, pp. 244, Plenum Press: New York, 1993.

14. Faustini, F.; Demunari, S.; Panzevi, A.; Villa, V.; Gandolfi, C. A. Tetrahedron Lett. 1981, 22, 4533.

15. Keck, R.; Rétey, J. Helv. Chim. Acta, 1980, 63, 769.

16. Serrano, J. L.; Sierra, T.; Ros, M. B.; Ezcurra, A.; Zubia, J. J. Am. Chem. Soc. 1992, 114, 7645.

17. Mitsunobu, O. Synthesis, 1981, 1.

18. Svensson, M.; Helgee, B.; Skarp, K.; Andersson, G. J. Mater. Chem. 1998, 8, 353.

19. Vogel, A. I.; A Text-book of Practical Organic Chemistry: Including Qualitative Organic Analysis, $3^{\text {rd }}$ ed., Longmans: London, p. 782, 1956.

20. Hsiue, G.-H.; Chen, J.-H. Macromolecules, 1995, 28, 4366.

21. Portugall, M.; Ringsdorf, H.; Zentel, R. Makromolekulare Chemie-Macromolecular Chemistry and Physics 1982, 183, 2311.

22. Neises, B., Steglich, W. Angew. Chem., Int. Ed. Engl. 1978, 17, 522.

23. Gray, G. W.; Goodby, J. W.; Smectic Liquid Crystals. Textures and Structures. Leonard Hill, 1984.

24. Tschierske, C. J. Mater. Chem. 2001, 11, 2647.

25. Tsukruk, V. V.; Shilov, V. V. Polymer, 1990, 31, 1793.

26. Craig, A. A.; Imrie, C. T. Macromolecules, 1999, 32, 6215.

27. Imrie, C. T.; Schleeh, T.; Karasz, F. E.; Attard, G. S. Macromolecules, 1993, 26, 539.

Received: July 5, 2005

Published on the web: February 13, 2006 
Synthesis and Mesomorphic Properties of Side Chain Liquid-Crystalline Biphenyl-Phenyl Polyacrylates

Olga M. S. Ritter, Nádya P. da Silveira, and Aloir A. Merlo*

Instituto de Química, Universidade Federal do Rio Grande do Sul, Av. Bento Gonçalves, 9500, Campus do Vale, 91501-970 Porto Alegre-RS, Brazil

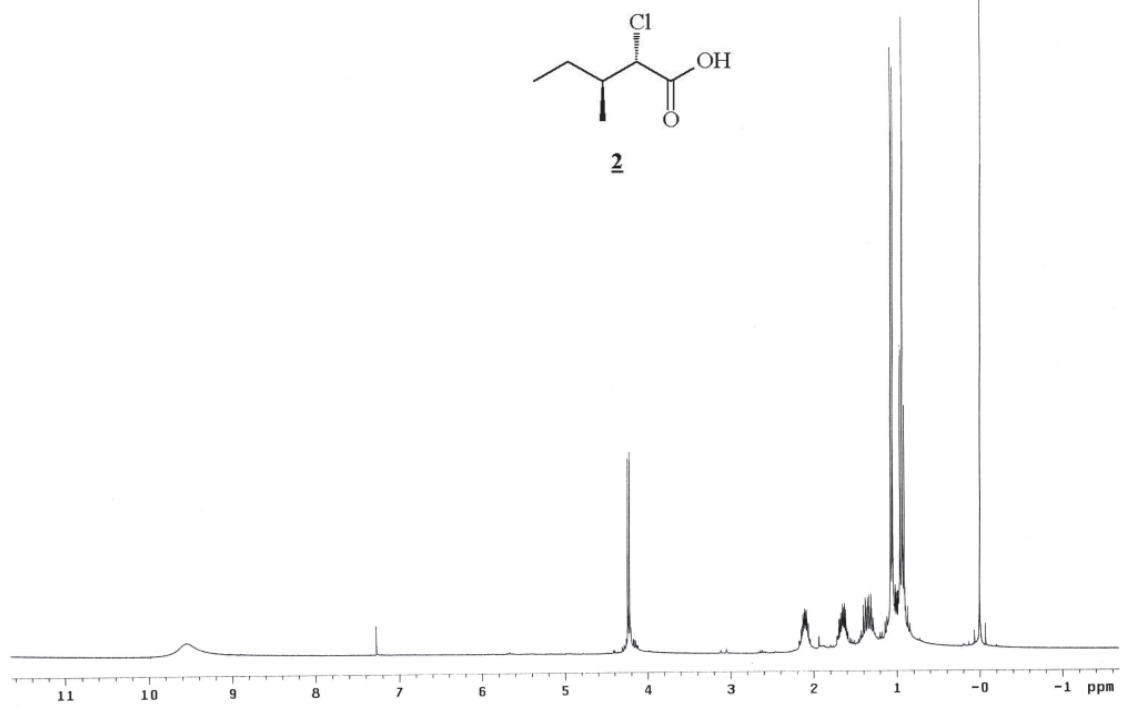

Figure S1. ${ }^{1} \mathrm{H} \mathrm{NMR}\left(\mathrm{CDCl}_{3}, 300 \mathrm{MHz}\right)$ for compound 2.<smiles>CCC(C)C(Cl)C(=O)O</smiles>

$\underline{2}$

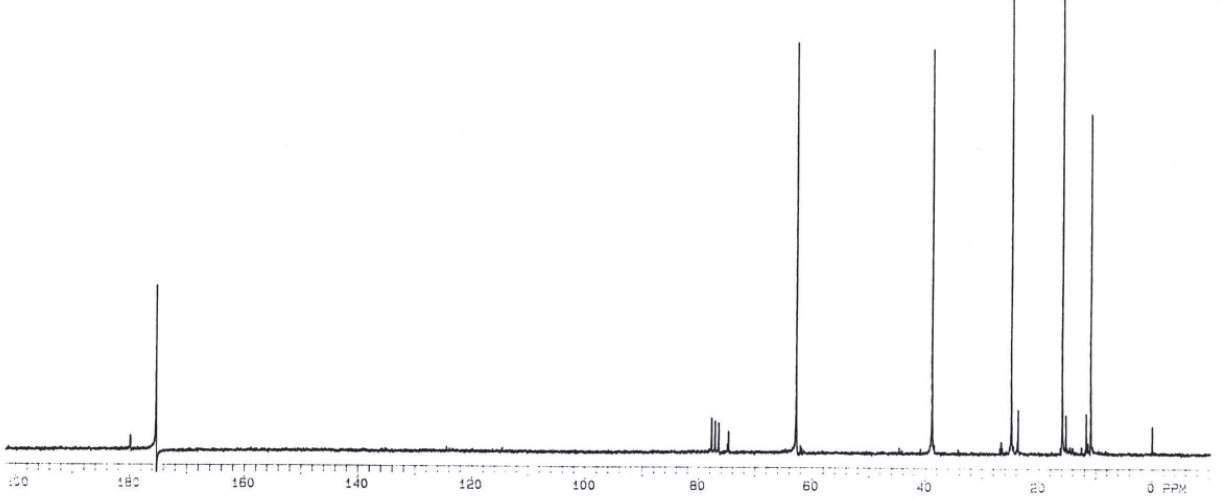

Figure S2. ${ }^{13} \mathrm{C} \mathrm{NMR}\left(\mathrm{CDCl}_{3}, 50 \mathrm{MHz}\right)$ for compound 2.

*e-mail: aloir@iq.ufrgs.br 


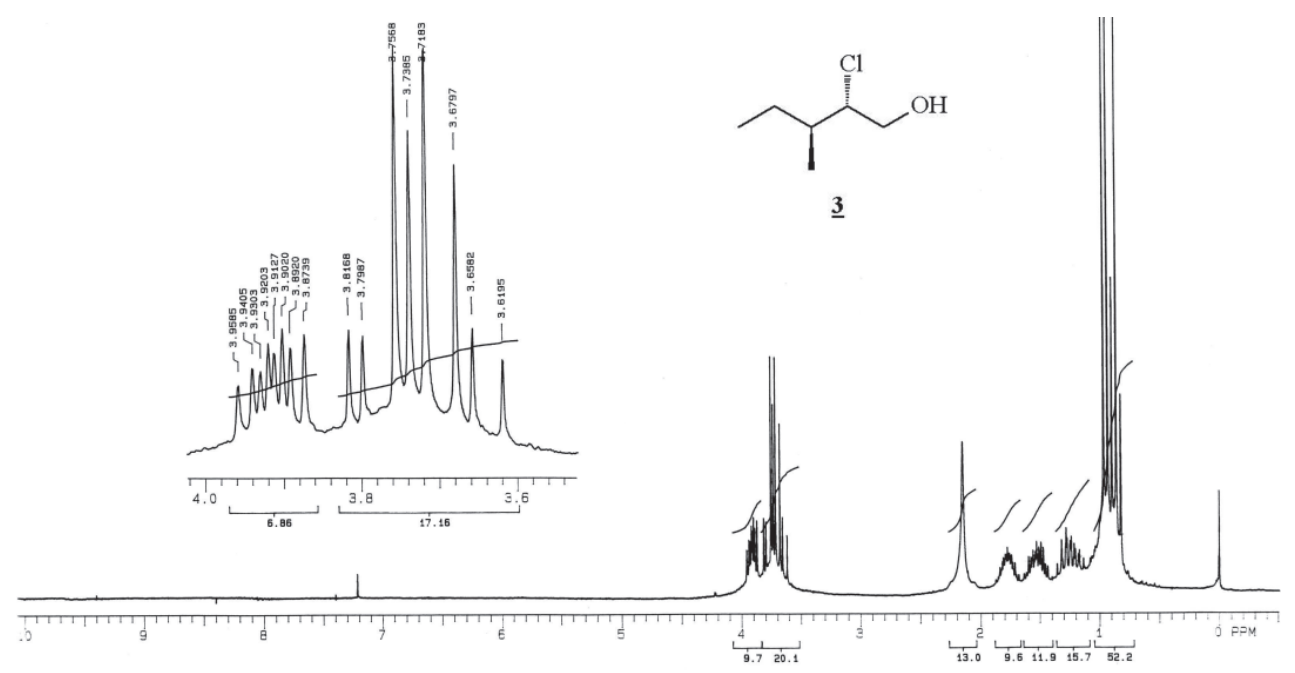

Figure S3. ${ }^{1} \mathrm{H} \mathrm{NMR}\left(\mathrm{CDCl}_{3}, 200 \mathrm{MHz}\right)$ for compound 3.

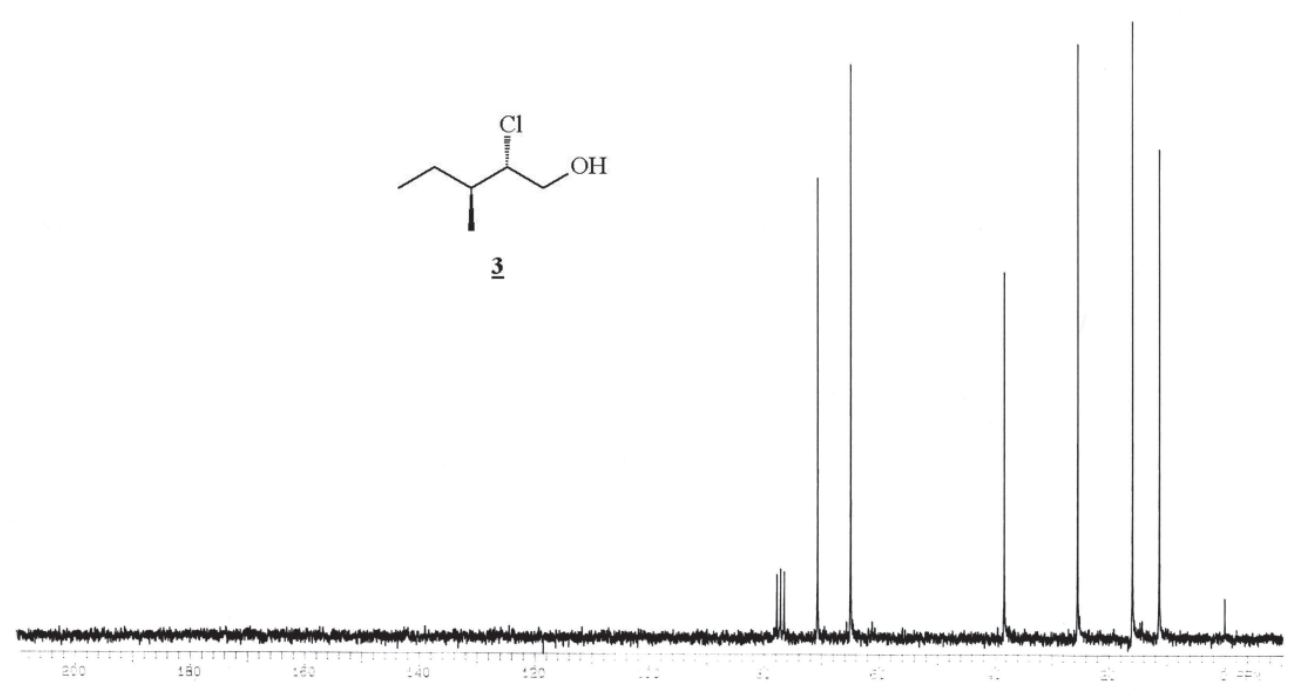

Figure S4. ${ }^{13} \mathrm{C} \mathrm{NMR}\left(\mathrm{CDCl}_{3}, 50 \mathrm{MHz}\right)$ for compound 3.

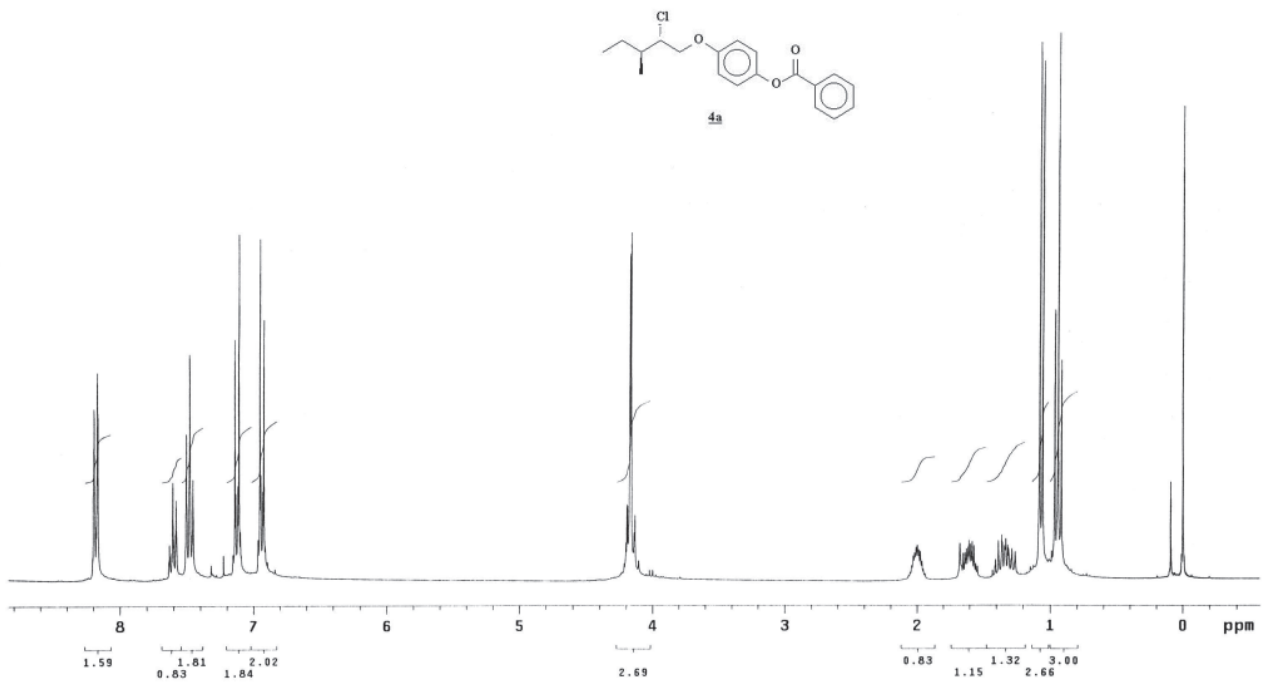

Figure S5. ${ }^{1} \mathrm{H} \mathrm{NMR}\left(\mathrm{CDCl}_{3}, 300 \mathrm{MHz}\right)$ for compound $\mathbf{4 a}$. 


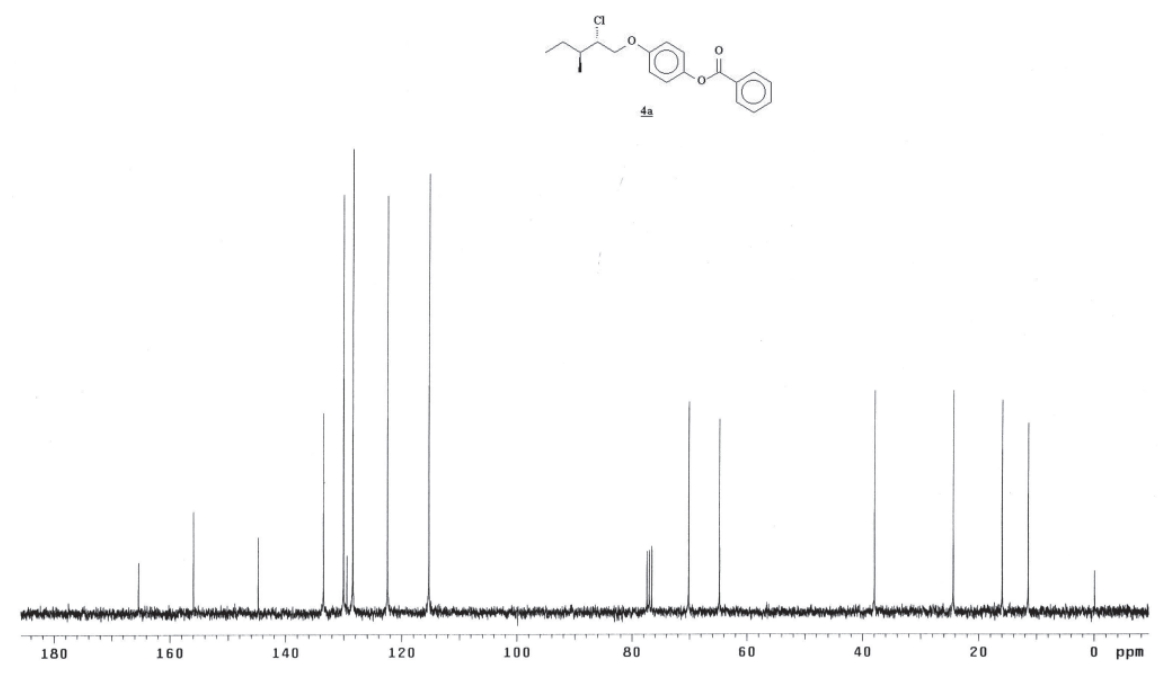

Figure S6. ${ }^{13} \mathrm{C} \mathrm{NMR}\left(\mathrm{CDCl}_{3}, 75 \mathrm{MHz}\right)$ for compound $\mathbf{4 a}$.

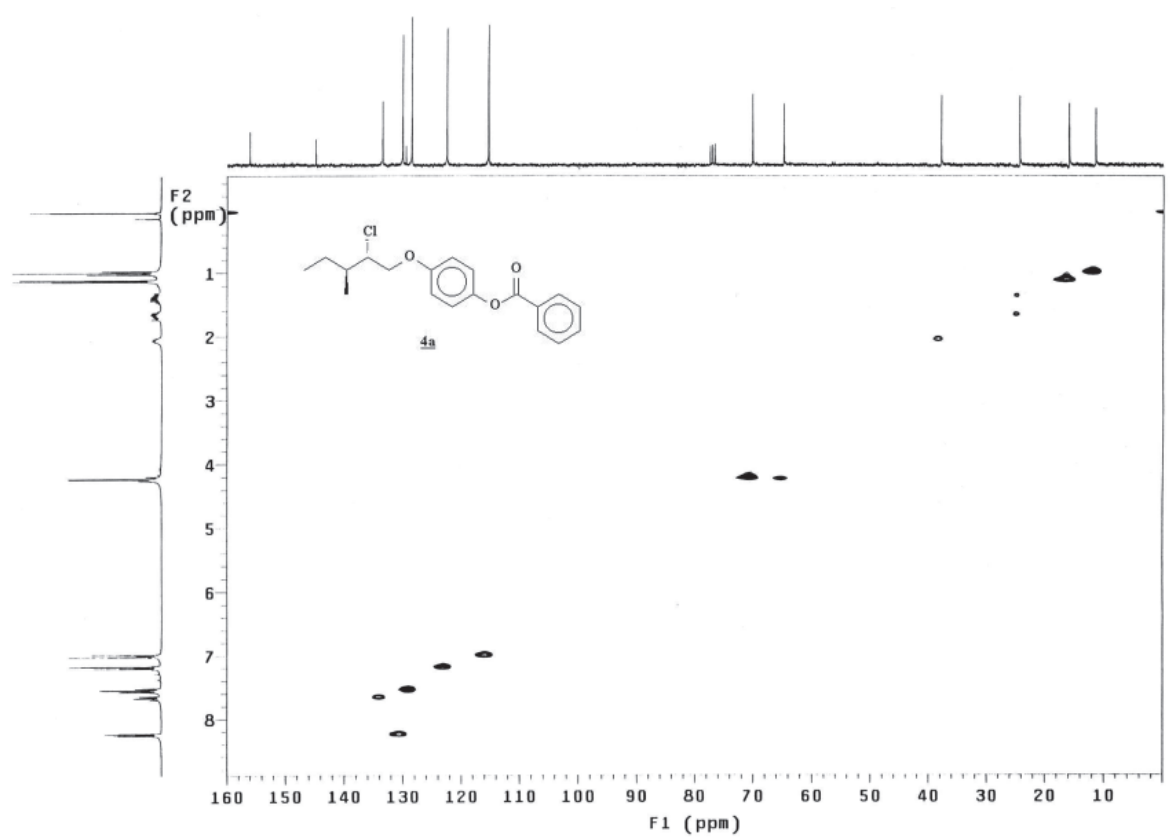

Figure S7. $\mathrm{HMQC}\left({ }^{1} \mathrm{H}^{13} \mathrm{C} \mathrm{NMR}, \mathrm{CDCl}_{3}, 300 \mathrm{MHz} / 75 \mathrm{MHz}\right)$ for compound $4 \mathbf{a}$.

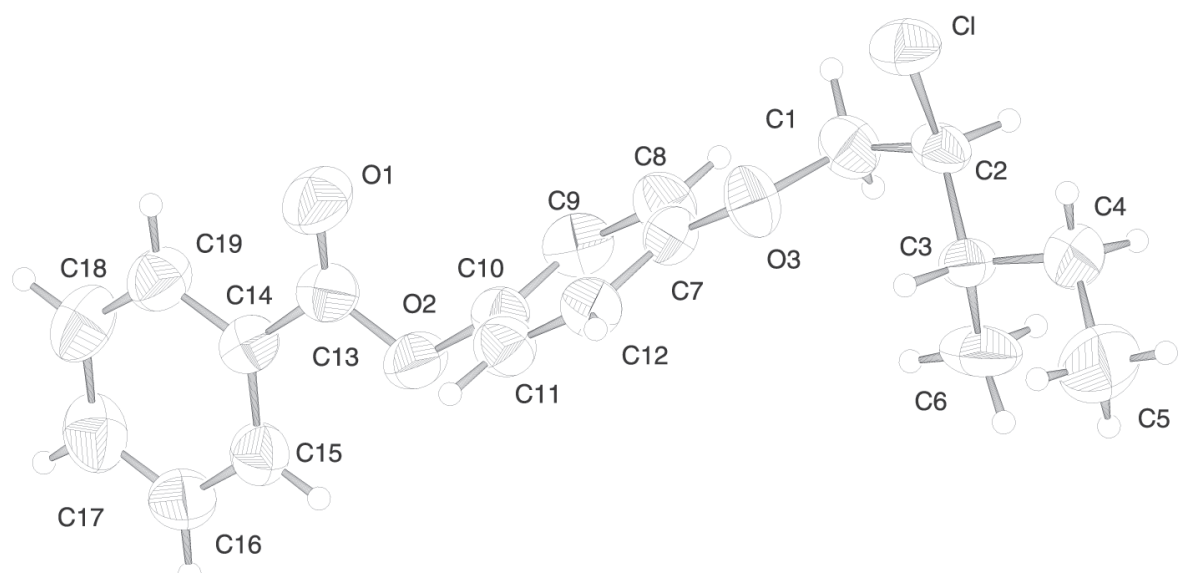

Figure S8. Molecular structure 4a. Perspective view and atom labelling. Thermal ellipsoids are given at the $50 \%$ probability level. Reference 11. 

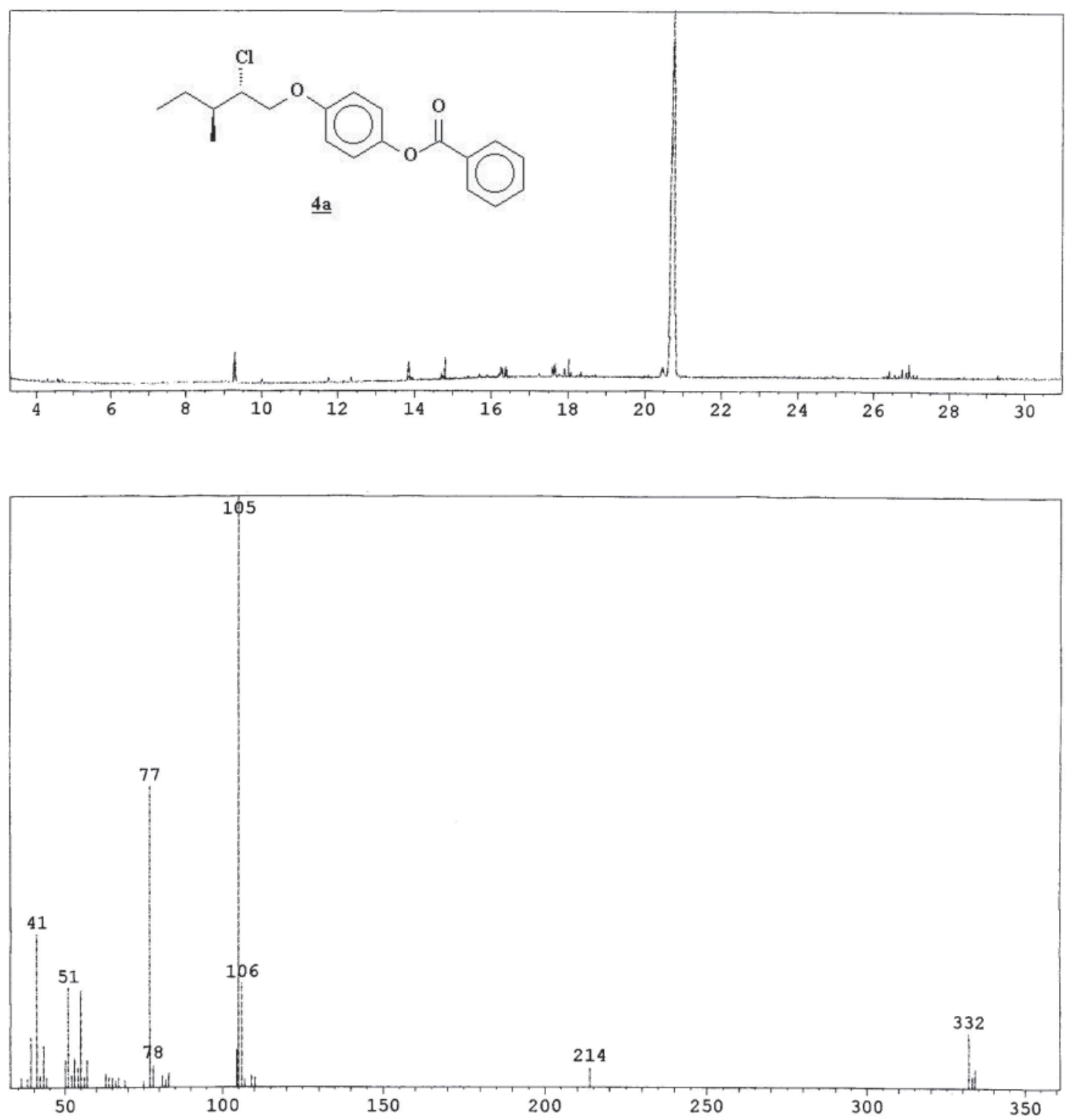

Figure S9. CG/MS (EI, $70 \mathrm{eV}$ ) for compound $\mathbf{4 a}$.

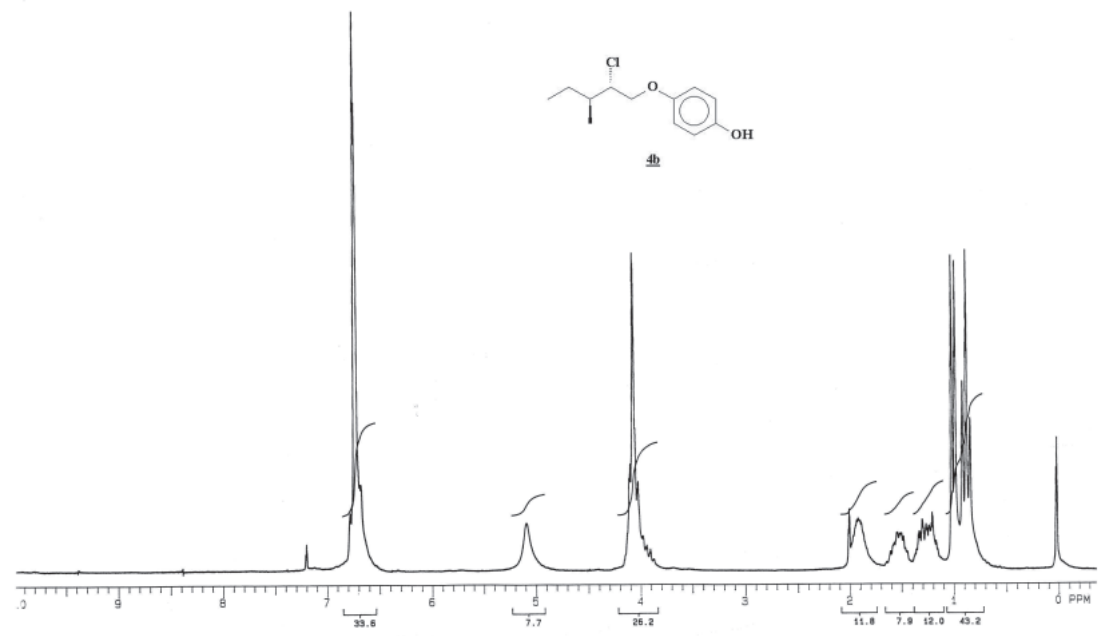

Figure S10. ${ }^{1} \mathrm{H}$ NMR $\left(\mathrm{CDCl}_{3}, 200 \mathrm{MHz}\right)$ for compound $\mathbf{4 b}$. 


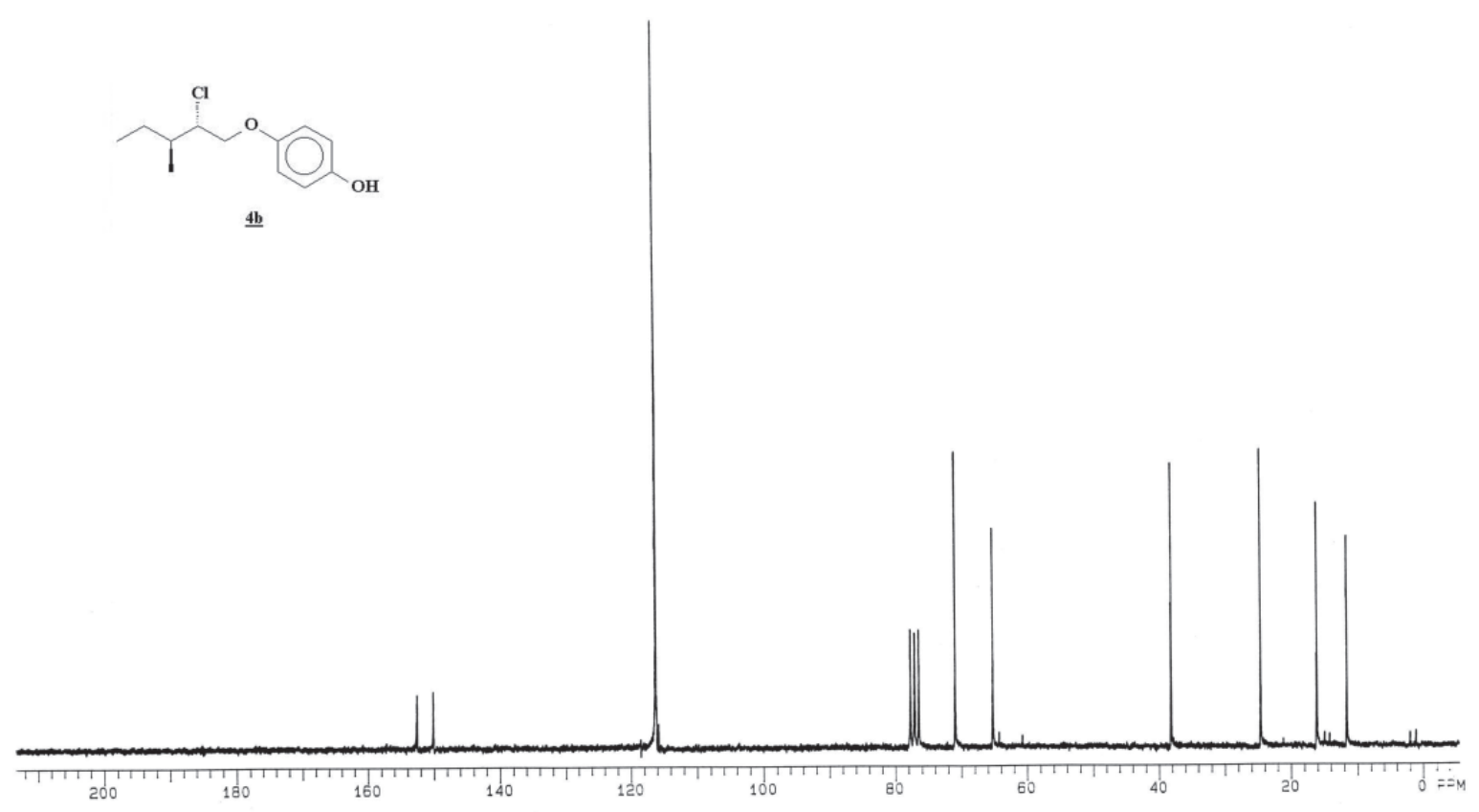

Figure S11. ${ }^{13} \mathbf{C}$ NMR $\left(\mathrm{CDCl}_{3}, 50 \mathrm{MHz}\right)$ for compound $\mathbf{4 b}$.
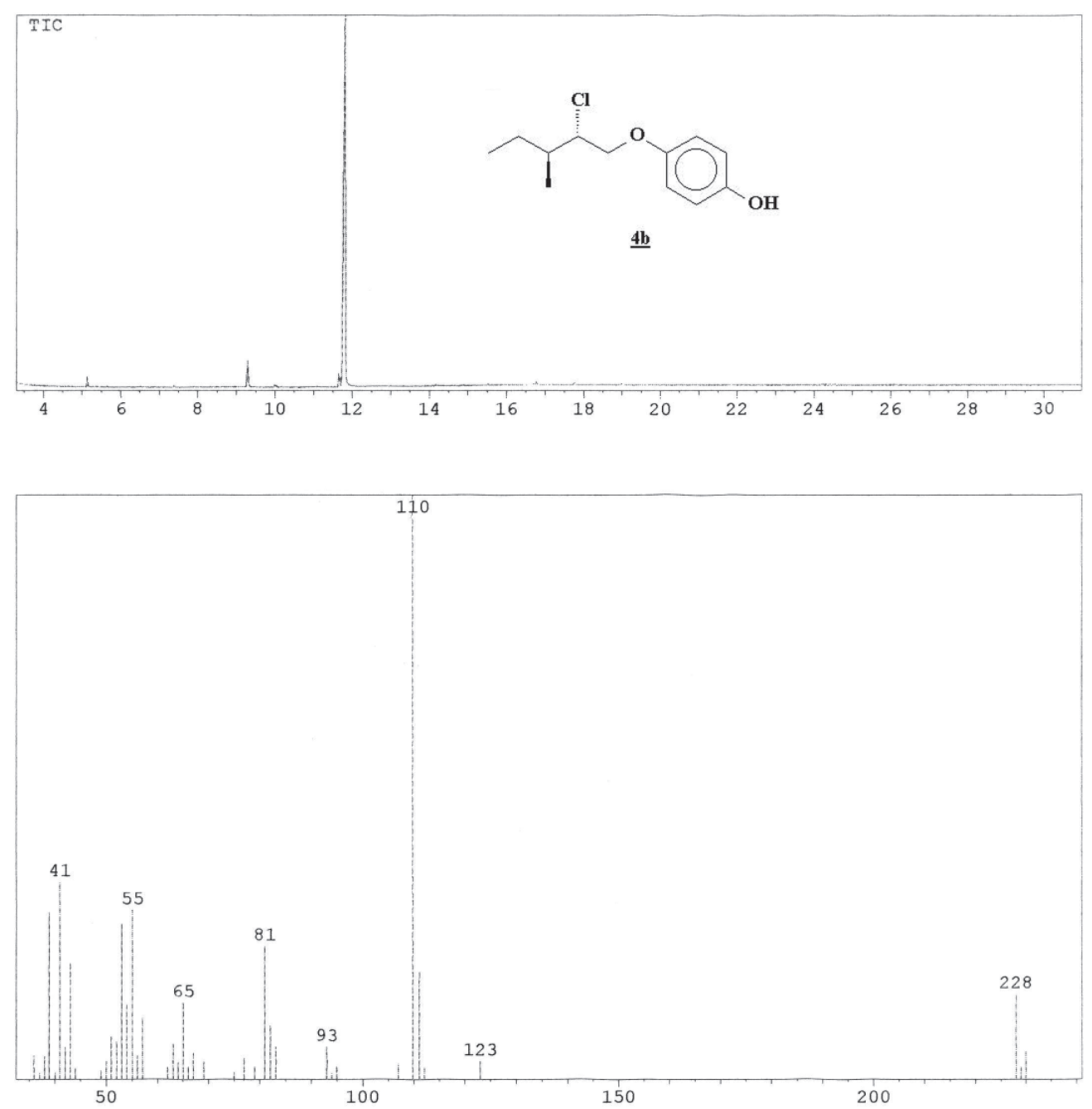

Figure S12. CG/MS (EI, $70 \mathrm{eV}$ ) for $\mathbf{4 b}$. 


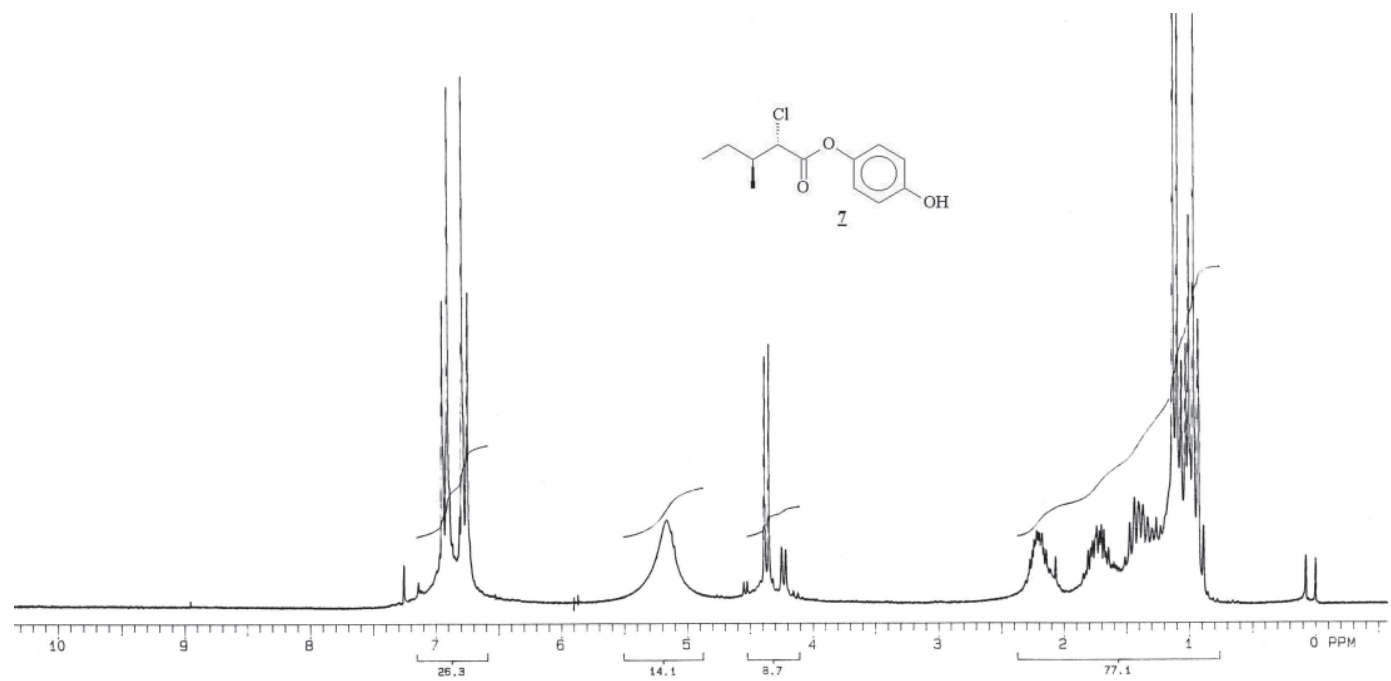

Figure S13. ${ }^{1} \mathrm{H} \mathrm{NMR}\left(\mathrm{CDCl}_{3}, 200 \mathrm{MHz}\right)$ for compound 7.<smiles>C=CC(=O)OCCCOc1ccc(-c2ccc(C(=O)O)cc2)cc1</smiles>
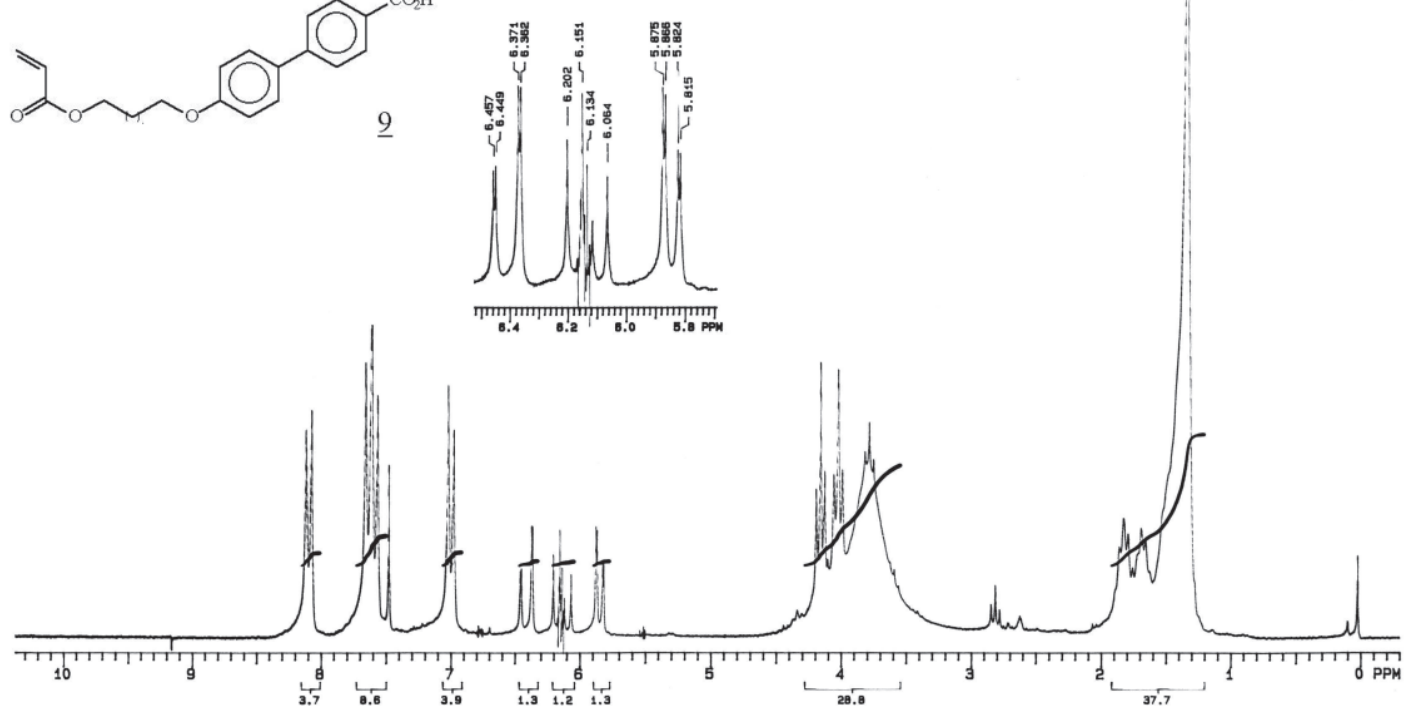

Figure S14. ${ }^{1} \mathrm{H} \mathrm{NMR}\left(\mathrm{CDCl}_{3} / \mathrm{DMSO}, 200 \mathrm{MHz}\right)$ for compound 9.

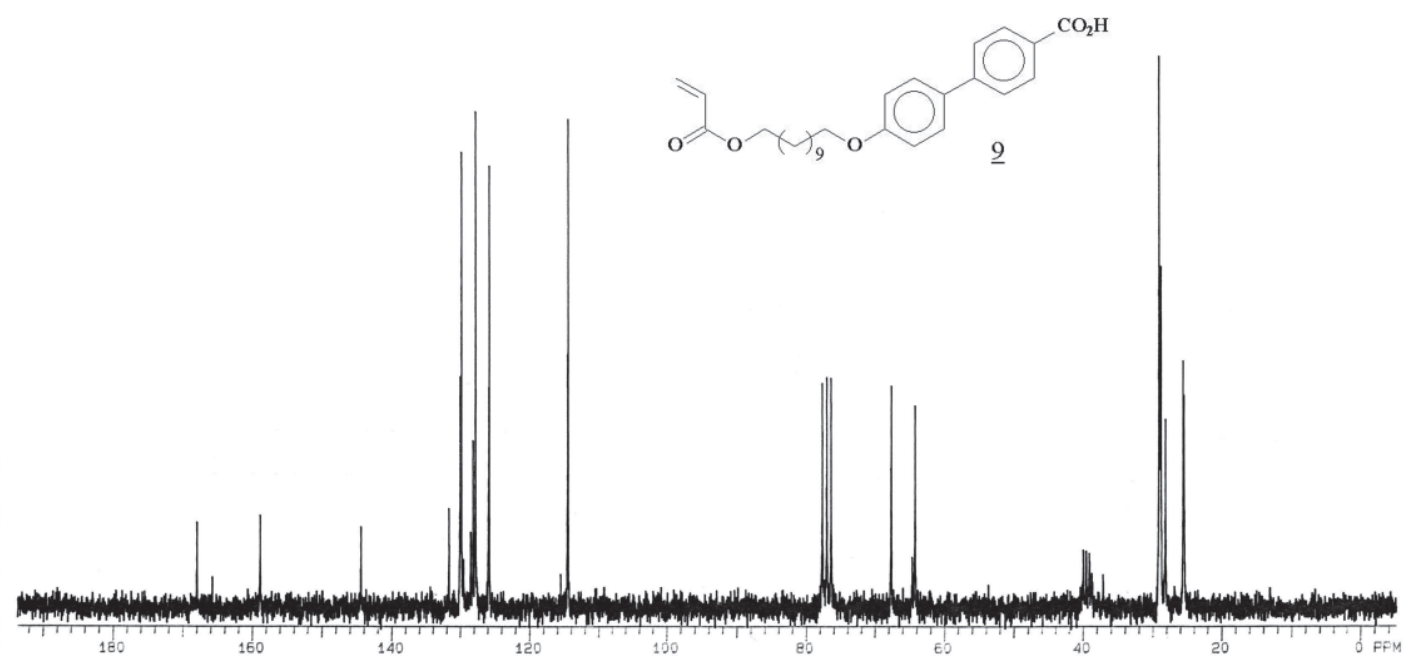

Figure S15. ${ }^{13} \mathrm{C}$ NMR $\left(\mathrm{CDCl}_{3} / \mathrm{DMSO}, 50 \mathrm{MHz}\right)$ for compound 9. 


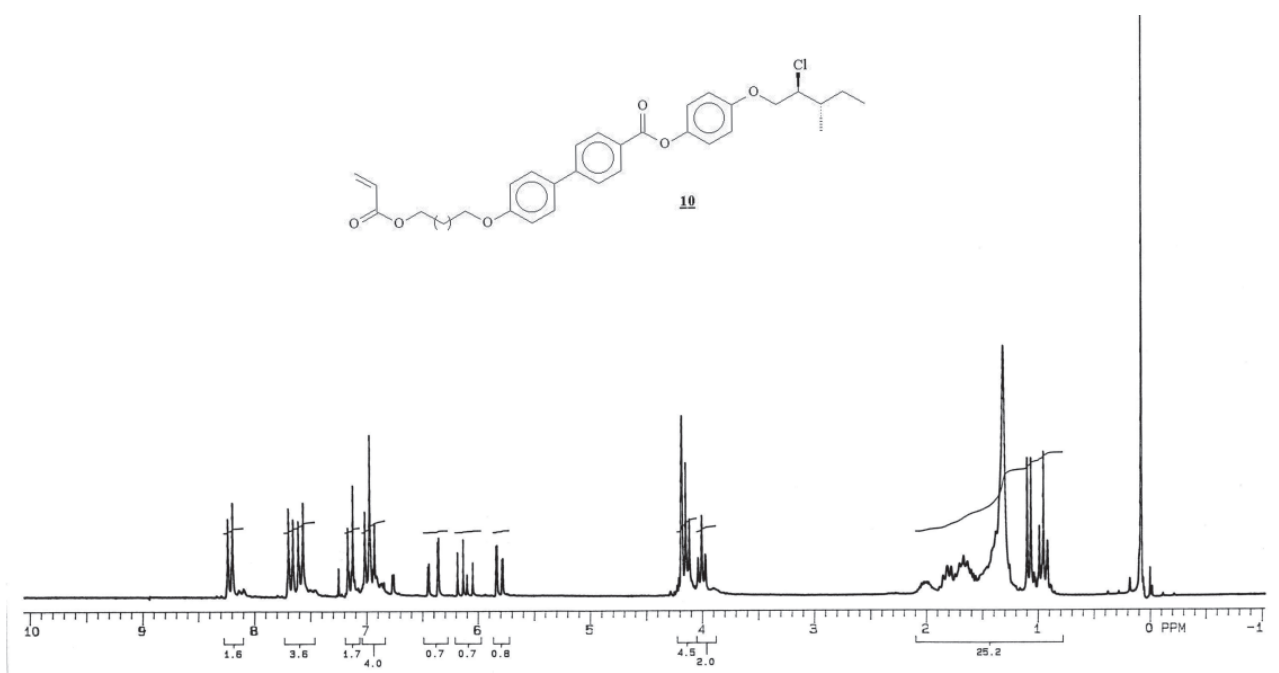

Figure S16. ${ }^{1} \mathrm{H} \mathrm{NMR}\left(\mathrm{CDCl}_{3}, 200 \mathrm{MHz}\right)$ for compound $\mathbf{1 0}$.

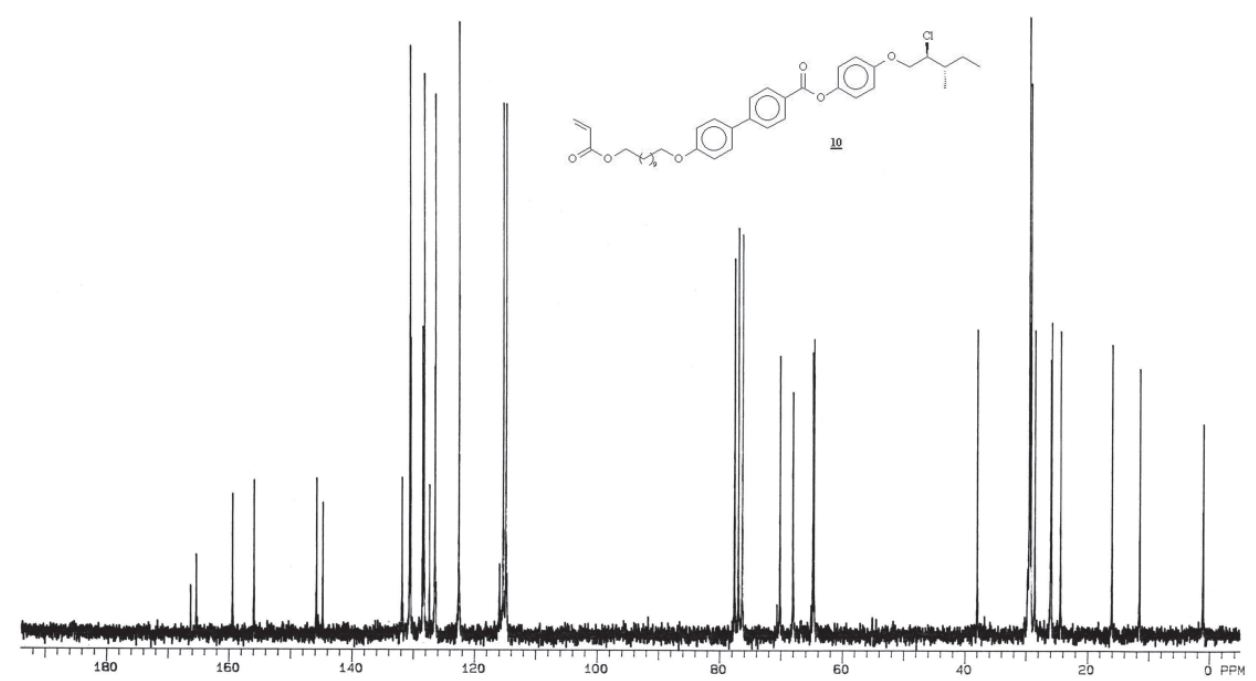

Figure S17. ${ }^{13} \mathrm{C} \mathrm{NMK}\left(\mathrm{CDCl}_{3}, \mathrm{SU} \mathrm{MHz}\right)$ tor compound $\mathbf{1 0}$.

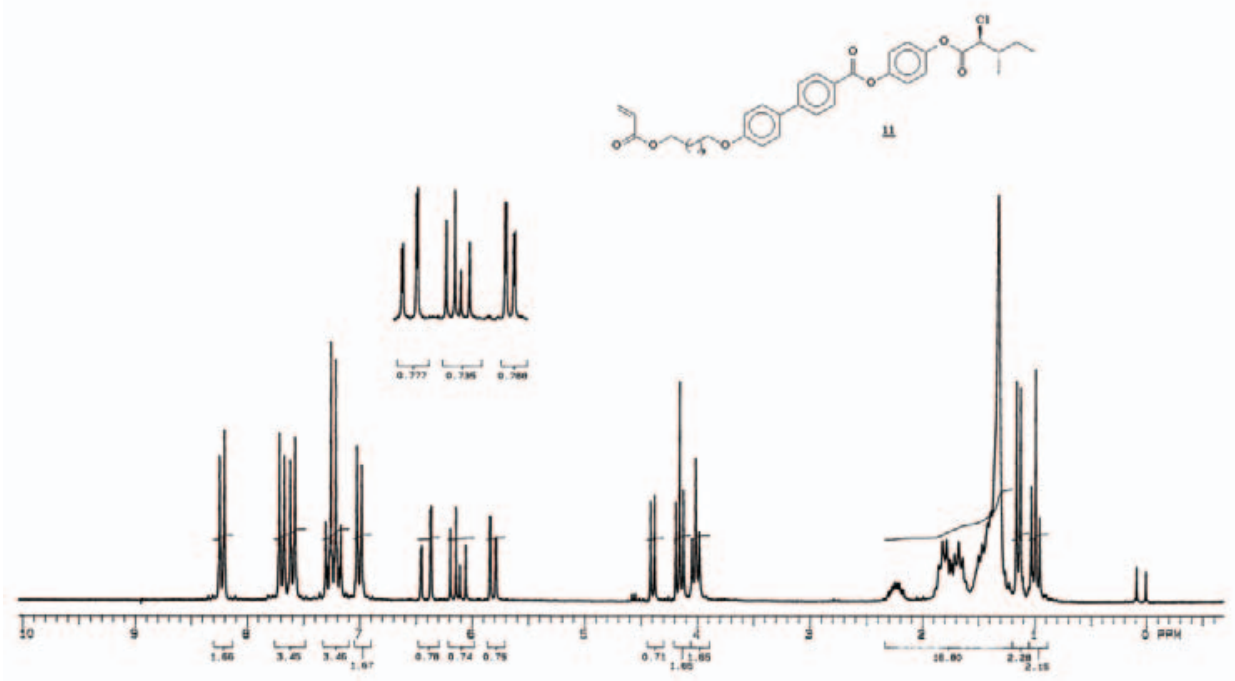

Figure S18. ${ }^{1} \mathrm{H} \mathrm{NMR}\left(\mathrm{CDCl}_{3}, 200 \mathrm{MHz}\right)$ for compound $\mathbf{1 1}$. 


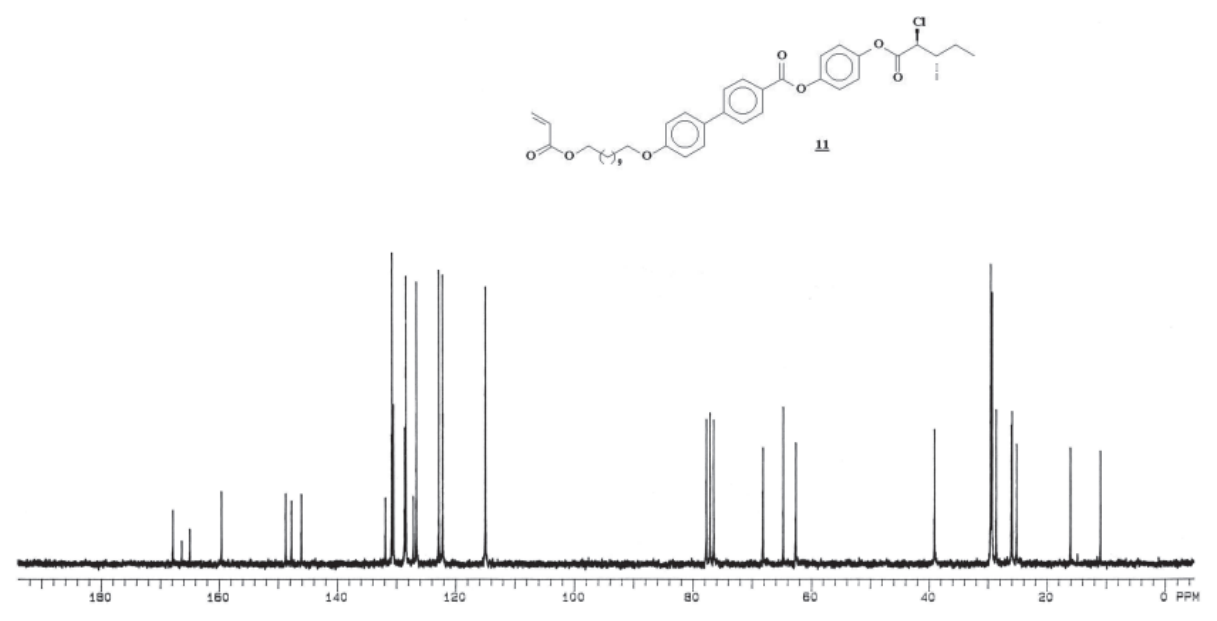

Figure S19. ${ }^{13} \mathrm{C}$ NMR $\left(\mathrm{CDCl}_{3}, 50 \mathrm{MHz}\right)$ for compound $\mathbf{1 1}$.

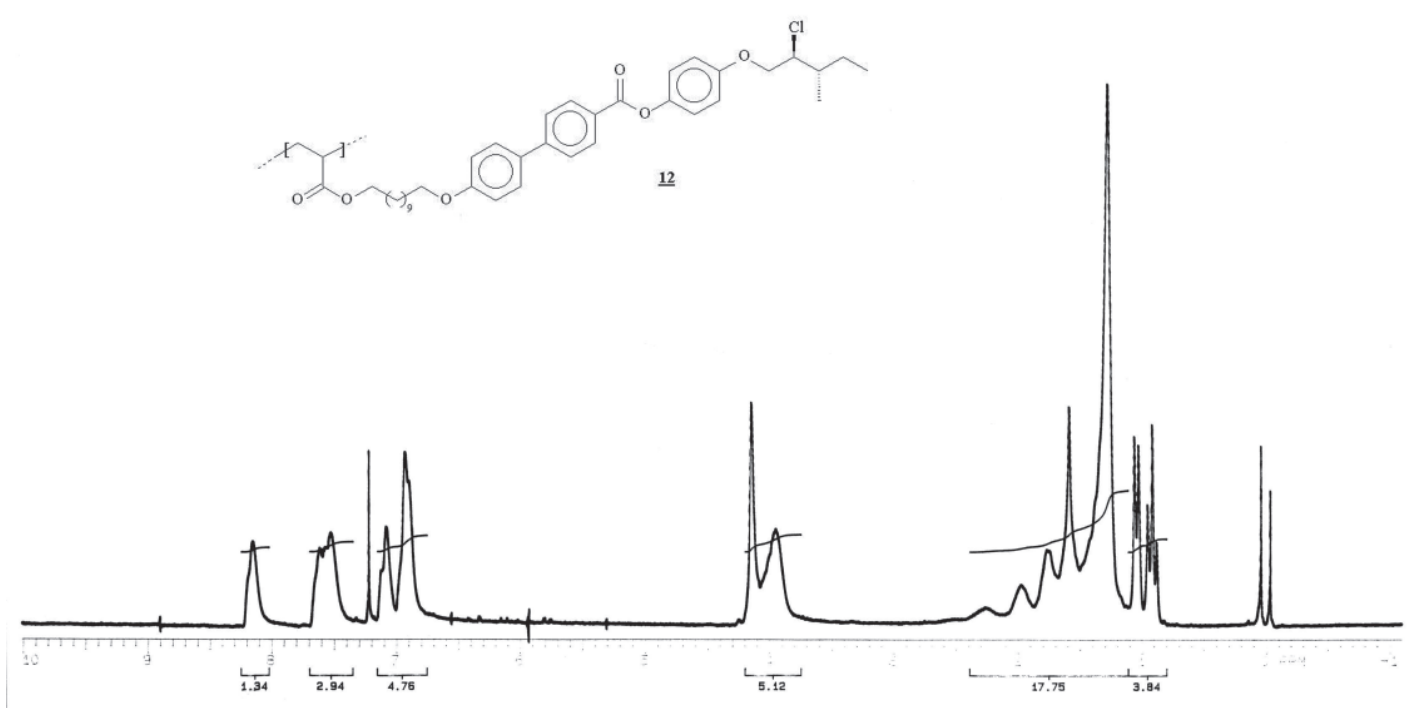

Figure S20. ${ }^{1} \mathrm{H} \mathrm{NMR}\left(\mathrm{CDCl}_{3}, 200 \mathrm{MHz}\right)$ for compound $\mathbf{1 2}$.

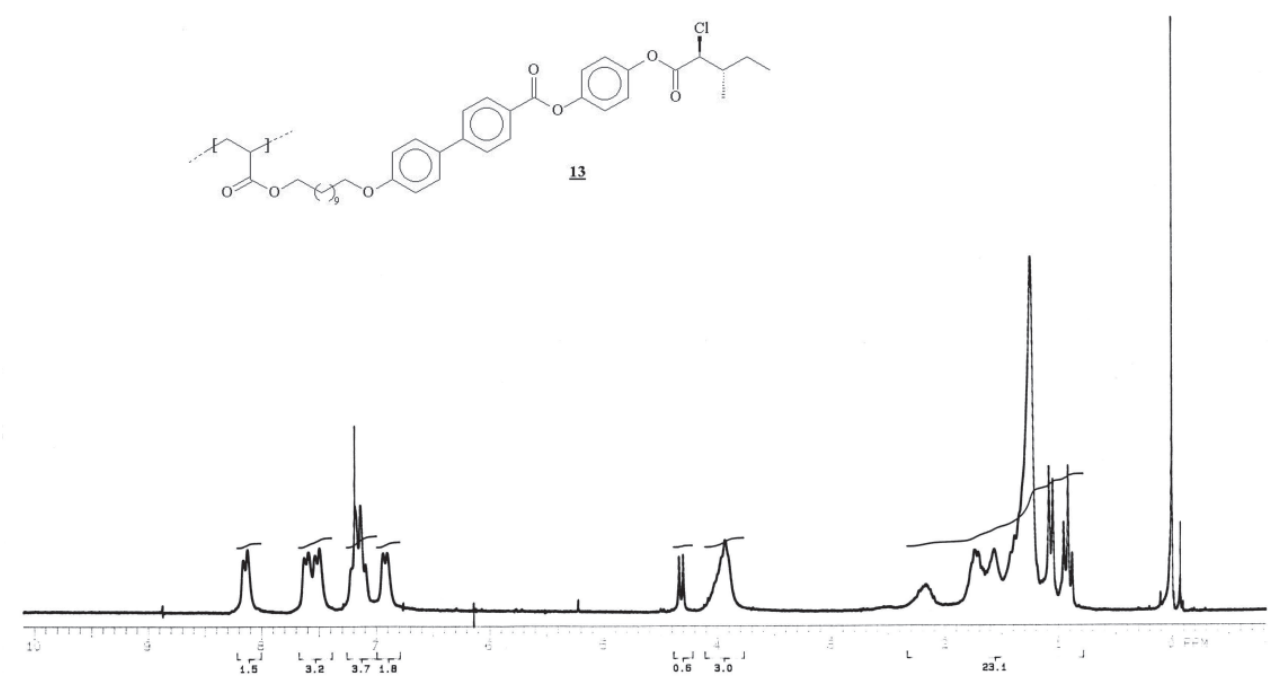

Figure S21. ${ }^{1} \mathrm{H} \mathrm{NMR}\left(\mathrm{CDCl}_{3}, 200 \mathrm{MHz}\right)$ for compound 13. 


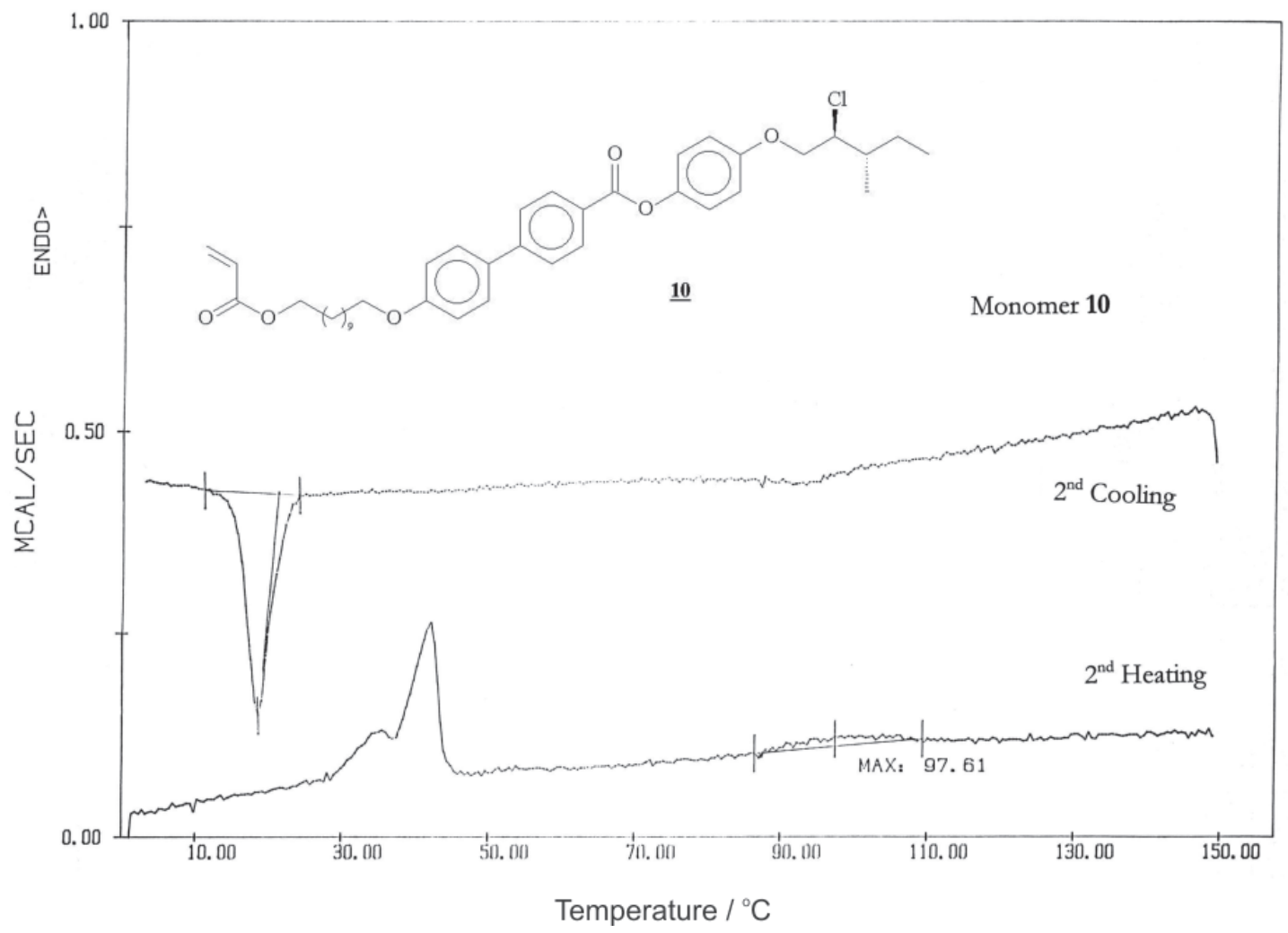

Figure S22. DSC Thermogram for monomer 10 on $2^{\text {nd }}$ at $5{ }^{\circ} \mathrm{C} \min ^{-1}$.

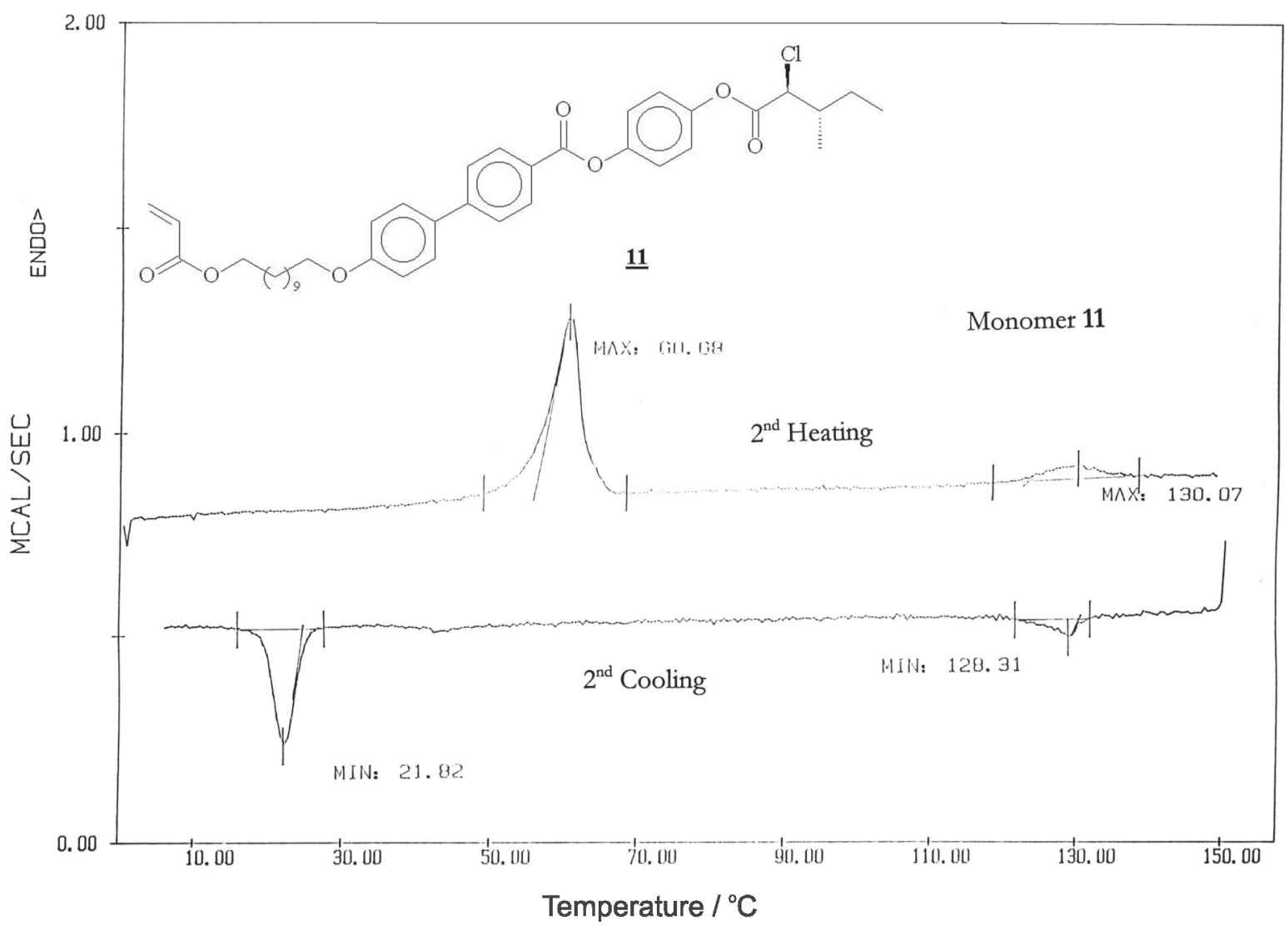

Figure S23. DSC Thermogram for monomer 11 on $2^{\text {nd }}$ cycle at $5{ }^{\circ} \mathrm{C} \mathrm{min}^{-1}$. 


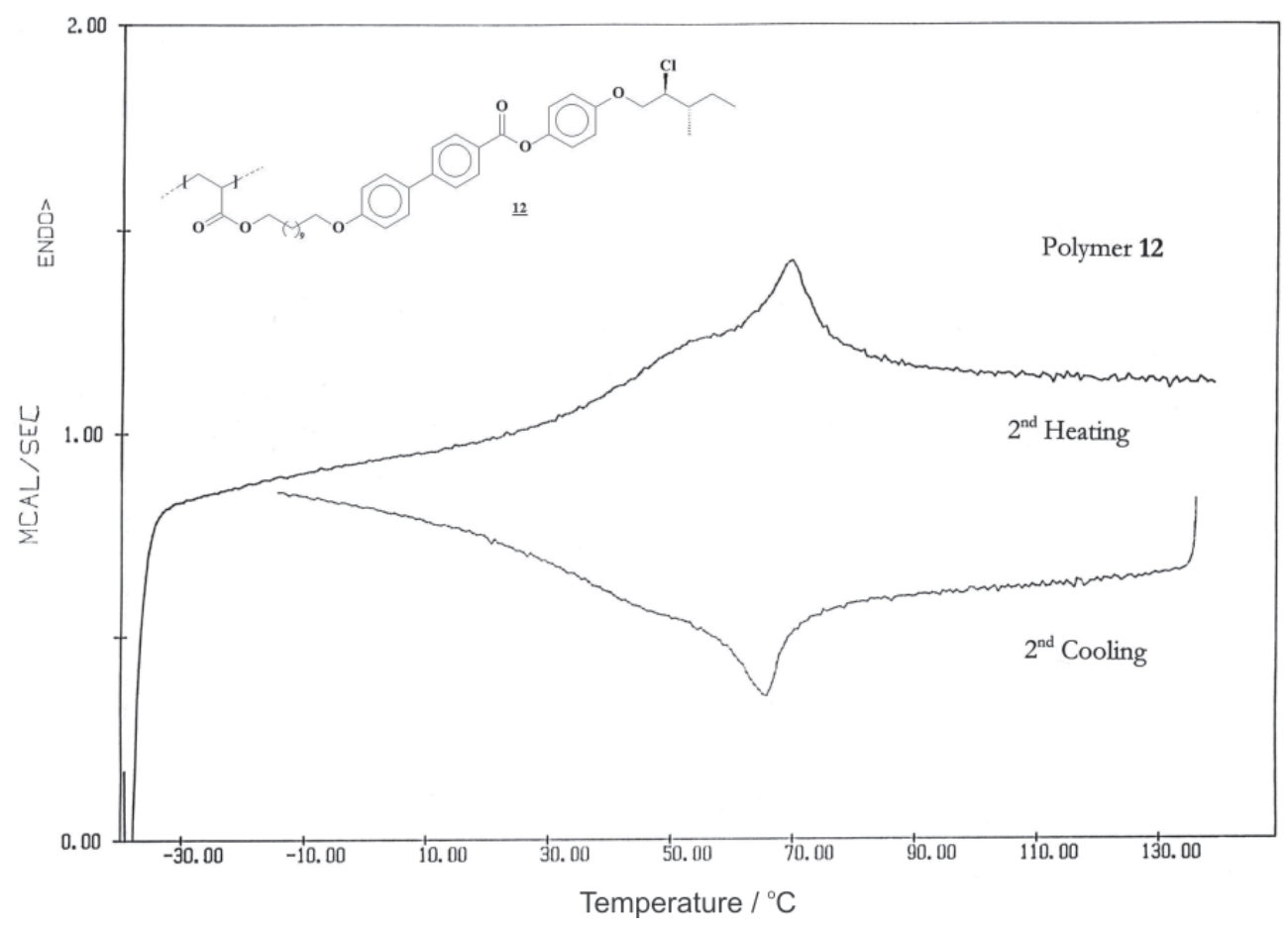

Figure S24. DSC Thermogram for polymer 12 on $2^{\text {nd }}$ cycle at $10{ }^{\circ} \mathrm{C} \mathrm{min}^{-1}$.

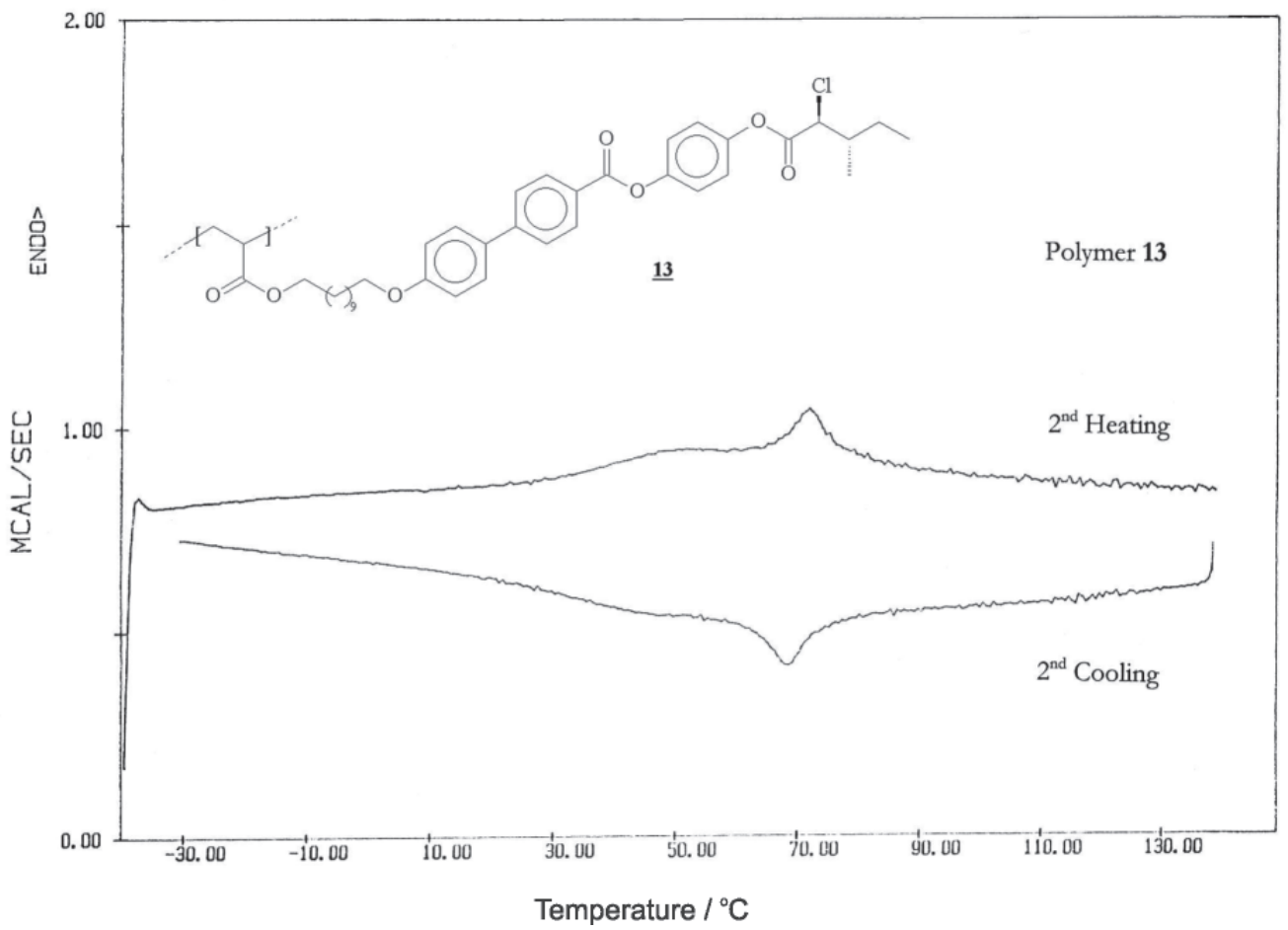

Figure S25. DSC Thermogram for polymer 13 on $2^{\text {nd }}$ cycle at $10{ }^{\circ} \mathrm{C} \mathrm{min}^{-1}$. 


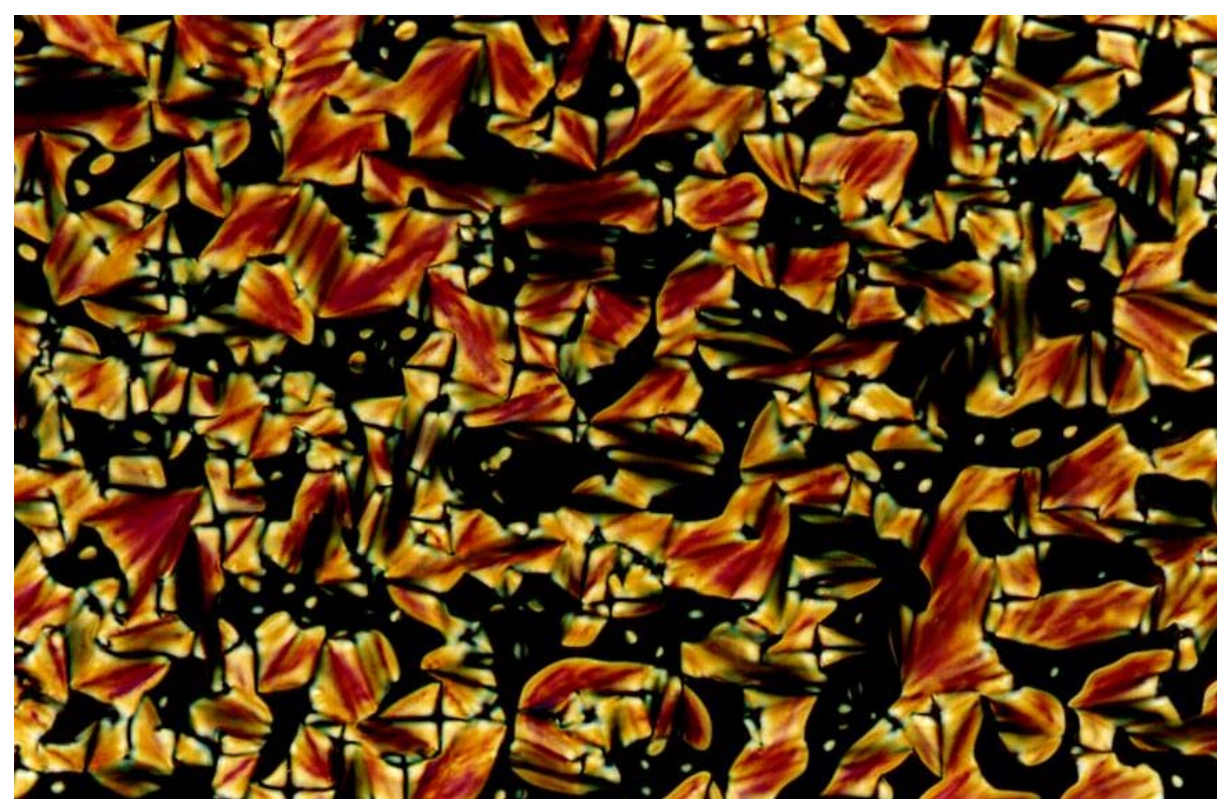

Figure S26. Texture of the smectic $\mathrm{A}^{*}$ phase for $\mathbf{1 0}$ on cooling at $94{ }^{\circ} \mathrm{C}(40 \mathrm{x})$

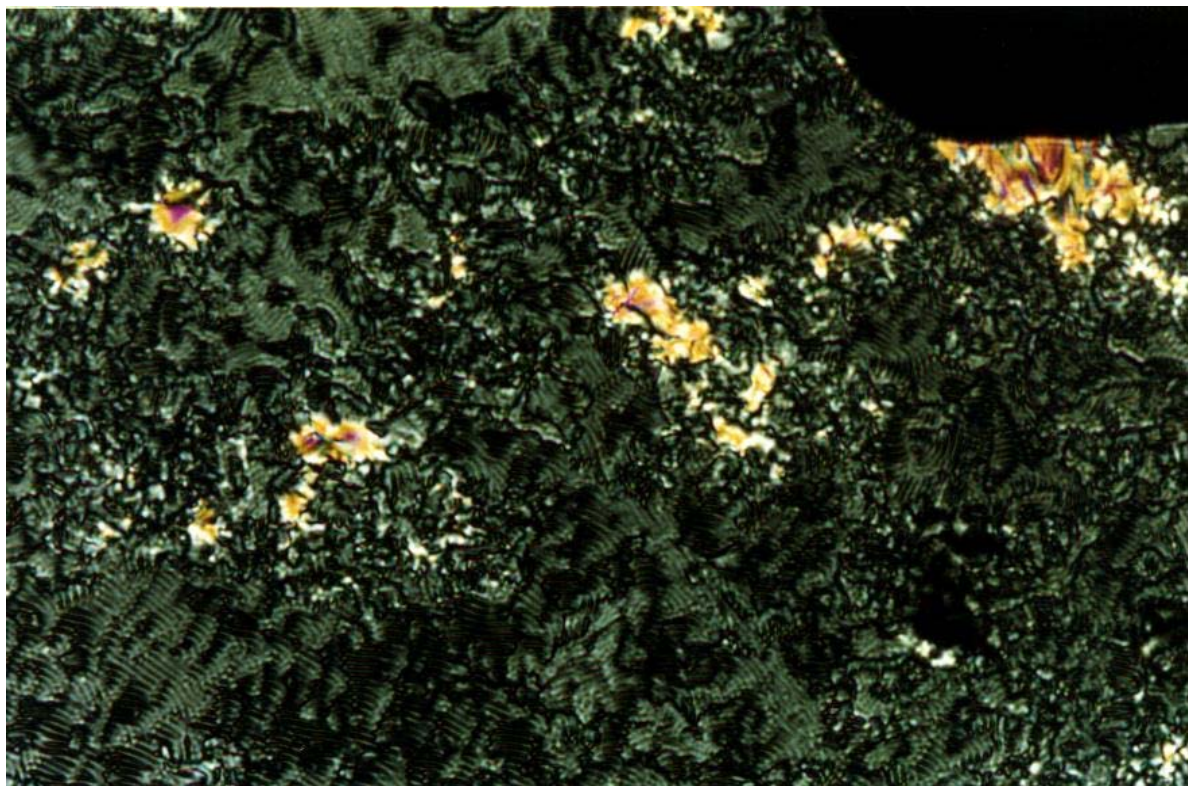

Figure S27. Texture of the smectic $\mathrm{C}^{*}$ for $\mathbf{1 1}$ on cooling at $65^{\circ} \mathrm{C}(40 \mathrm{x})$ 

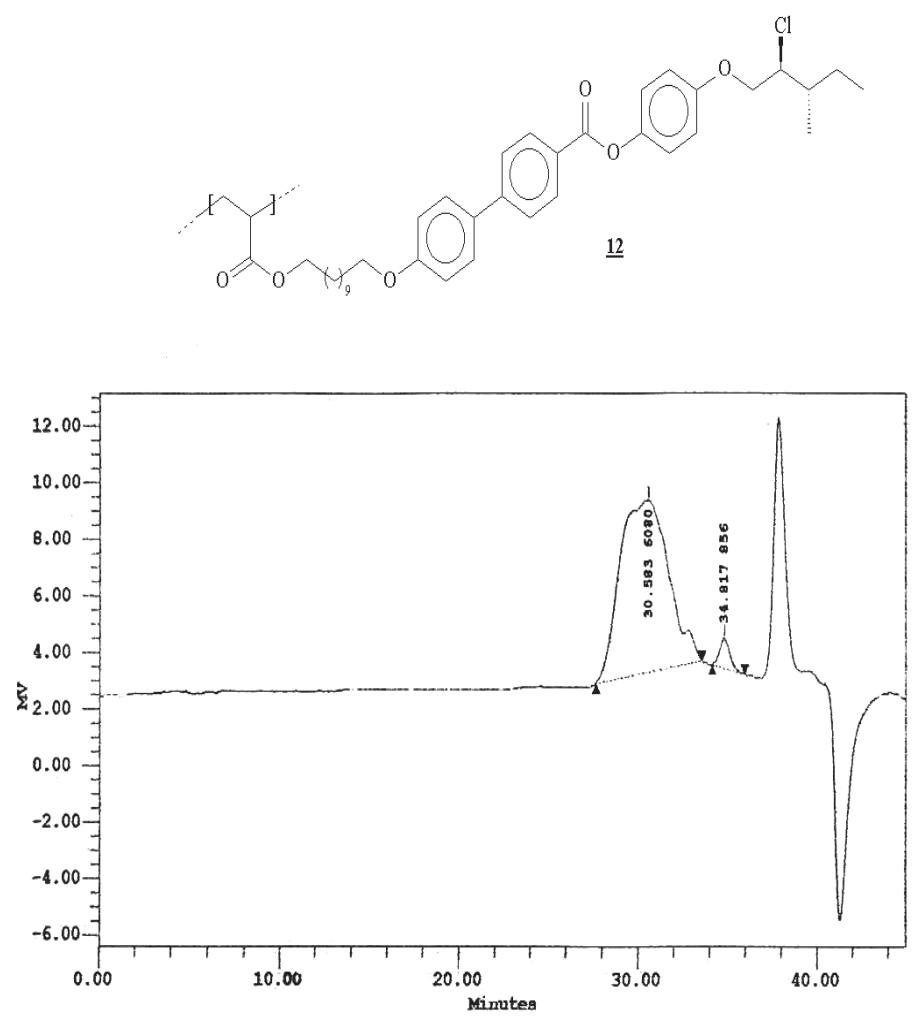

Figure S28. GPC chromatogram for polymer 12.
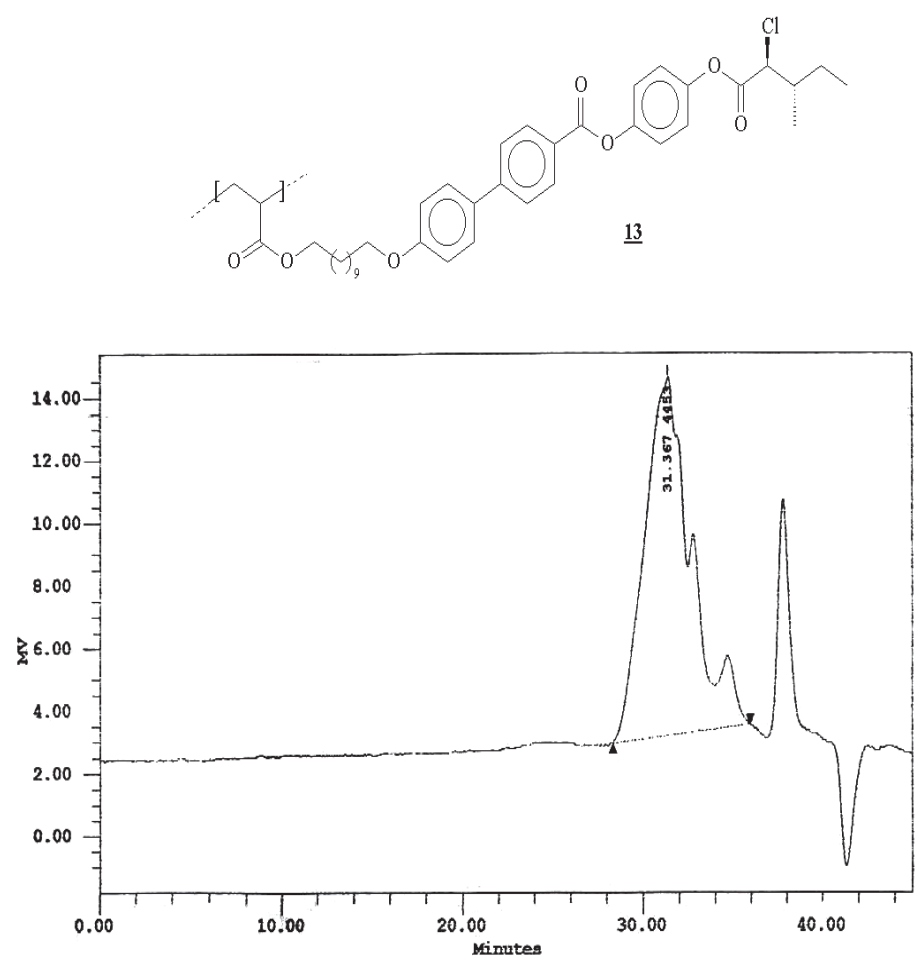

Figure S29. GPC chromatogram for polymer 13. 